\title{
Light-powered autonomous and directional molecular motion of a dissipative self-assembling system
}

Giulio Ragazzon, Massimo Baroncini, Serena Silvi, Margherita Venturi and Alberto Credi*

\section{Table of Contents}

1. General Methods

2. NMR Spectroscopy

3. UV-Visible Spectroscopy

4. References
Page S2

S8

S9

$\mathrm{S} 21$ 


\section{General Methods}

Materials and Characterization Methods. Compound 1 was synthesized according to previously published procedures ${ }^{1}$. Compounds $E-\mathbf{2}^{+}, \mathbf{3}^{+}$and $E E-\mathbf{4}^{+}$were available from previous investigations $^{2}$. Solvents were dried according to literature procedures. The ${ }^{1} \mathrm{H}$ and ${ }^{13} \mathrm{C} N M R$ spectra were recorded at $298 \mathrm{~K}$ in $\mathrm{CD}_{2} \mathrm{Cl}_{2}$ with a Varian Mercury 400 spectrometer with the deuterated solvent as the lock and the residual solvent as the internal standard.

UV-Visible Spectroscopy and Photochemistry. Absorption spectra were recorded with a Varian Cary 50Bio, Agilent Technologies Cary 300 and Perkin Elmer Lambda45 spectrophotometers, on air equilibrated $\mathrm{CH}_{2} \mathrm{Cl}_{2}$ (Romil) solutions at room temperature (ca. $20^{\circ} \mathrm{C}$ ), with concentrations ranging from $1 \times 10^{-5}$ to $1 \times 10^{-3} \mathrm{M}$. Solutions were examined in $1-\mathrm{cm}$ spectrofluorimetric quartz cells. Dedicated spectrophotometric cells endowed with two compartments separated by a quartz wall were employed for a careful determination of the sum of the absorption spectra of the separated components (unmixed solutions) and the absorption spectrum of their complex (mixed solutions). The experimental error on the wavelength values was estimated to be $\pm 1 \mathrm{~nm}$. Photochemical reactions were performed on $\mathrm{CH}_{2} \mathrm{Cl}_{2}$ solutions at room temperature (ca. $20^{\circ} \mathrm{C}$ ), thoroughly stirred and eventually argon-purged (if irradiated for more than typically $1 \mathrm{~h}$ ), by using a Hanau Q400 or Helios Italquartz Polymer 125 medium pressure Hg lamp (respectively 150 and 125 W); ${ }^{1} \mathrm{H}$ NMR photochemical isomerization experiments were performed in air equilibrated $\mathrm{CD}_{2} \mathrm{Cl}_{2}$ solutions irradiated directly inside the NMR tube. The selection of the desired irradiation wavelength $(287,365$ or $436 \mathrm{~nm})$ was accomplished by the use of an appropriate interference filter. The number of incident photons, determined by ferrioxalate actinometry in its micro version ${ }^{3}$, was $2.4 \times 10^{-8}$ Einstein $\min ^{-1}$ at $287 \mathrm{~nm}, 1.0 \times 10^{-7}$ Einstein $\min ^{-1}$ at $365 \mathrm{~nm}$, and $2.4 \times 10^{-7}$ Einstein min $^{-1}$ at $436 \mathrm{~nm}$. The $E \rightarrow Z$ photoisomerization quantum yield $\left(\lambda_{\text {irr }}=365 \mathrm{~nm}\right)$ was determined from the disappearance of the $\pi \pi^{*}$ absorption band of the azobenzene unit of the reactant at low conversion percentages $(<10 \%$; extrapolation to $t=0$ was made). The fraction of light transmitted at the irradiation wavelength was taken into account in the calculation of the yields. The experimental error on the quantum yield values was estimated to be $\pm 10 \%$.

UV-Visible Spectroscopic Measurements. Reaction kinetic profiles were collected on airequilibrated $\mathrm{CH}_{2} \mathrm{Cl}_{2}$ (Romil) solutions at $20^{\circ} \mathrm{C}$. Threading processes were investigated by monitoring the time-dependent spectroscopic changes observed after addition of a concentrated (typically $\mathrm{mM}$ ) solution of the axle to a more diluted ring solution. Dethreading reactions were triggered by dilution and were studied by monitoring the time-dependent spectroscopic changes observed after rapid mixing of the investigated complex with the solvent. Thermal $Z \rightarrow E$ 
isomerization reactions were performed at $20^{\circ} \mathrm{C}$ in the dark, monitoring the time-dependent absorption changes with a spectrophotometer. In all cases the data were elaborated by means of the SPECFIT fitting program ${ }^{4}$. Threading processes were modeled according to a mixed-order scheme, that is, second order (threading) and first order (dethreading) opposing reactions (equation S1)

$1+$ Guest $\underset{k_{\text {out }}}{\stackrel{k_{\text {in }}}{\rightleftarrows}}[$ (1 JGuest $]$

Dethreading processes and thermal $Z \rightarrow E$ isomerization reactions were modelled according to firstorder kinetics. The values reported in Table 1 are typically an average of at least 3 independent experiments. The estimated experimental error for $k_{\text {in }}$ values is $\pm 20 \%$; consequently, the error on the threading energy barriers is $\delta \Delta G^{\ddagger}$ in $\approx R T \delta k_{\text {in }} / k_{\text {in }}=0.20 R T \approx 0.12 \mathrm{kcal} \mathrm{mol}^{-1}$ at $20^{\circ} \mathrm{C}$. As for the dethreading rate constants, $\delta k_{\text {out }} / k_{\text {out }}=\left[\left(\delta k_{\text {in }} / k_{\text {in }}\right)^{2}+(\delta K / K)^{2}\right]^{1 / 2} \approx \pm 30 \%$; the error on the dethreading energy barriers is $\delta \Delta G_{\text {out }}^{\ddagger} \approx R T \delta k_{\text {out }} / k_{\text {out }}=0.30 R T \approx 0.18 \mathrm{kcal} \mathrm{mol}^{-1}$ at $20^{\circ} \mathrm{C}$.

Spectroscopic titrations. Stability constants were determined from titration curves obtained by measuring the luminescence intensity of $\mathbf{1}\left(\lambda_{\mathrm{exc}}=272 \mathrm{~nm}\right)$ upon addition of small aliquots of a concentrated solution of the considered guest to $2.5 \mathrm{~mL}$ of a dilute solution (typically, $50 \mu \mathrm{M}$ ) of 1 in $\mathrm{CH}_{2} \mathrm{Cl}_{2}$ at $20^{\circ} \mathrm{C}$. To minimize inner filter effects, the emission detection was performed on isosbestic point $(390 \mathrm{~nm})$. In the case of the $[\mathbf{1} \supset \mathbf{3}]^{+}$complex, the absorbance changes at $325 \mathrm{~nm}$ were used to obtain the binding isotherm, because the luminescence intensity of $\mathbf{1}$ is not affected by addition of $\mathbf{3}^{+}$. In all cases the constants were calculated by means of the SPECFIT fitting program according to a $1: 1$ binding model $^{4}$. The estimated experimental error on $K$ values is $\pm 20 \%$; consequently, the error on the free energy change values is $\delta \Delta G^{\circ} \approx R T \delta K / K=0.20 R T \approx 0.12 \mathrm{kcal}$ $\mathrm{mol}^{-1}$ at $20^{\circ} \mathrm{C}$.

Microscopic reversibility considerations. For a square network of chemical reactions such as that represented in Fig. S1, microscopic reversibility imposes that when the cycle is at thermodynamic equilibrium each individual process must be equilibrated and its net rate must be zero $\left(v_{1}=v_{2}=v_{3}=\right.$ $\left.v_{4}=0\right)$. The equilibrium constant of reaction $\mathrm{A} \leftrightarrows \mathrm{B}$ must correspond to the product of the equilibrium constants of reactions $\mathrm{A} \leftrightarrows \mathrm{D}, \mathrm{D} \leftrightarrows \mathrm{C}$ and $\mathrm{C} \leftrightarrows \mathrm{B}$. In other words, $K_{1}=K_{4} \times K_{3} \times 1 / K_{2}$, or

$K_{1} / K_{3}=K_{4} / K_{2}$

It should be noted that equation (S2) is not strictly valid when photochemical reactions are involved, as microscopic reversibility does not apply. However, the observation of a behaviour deviating from 
equation (S2) for the cycle shown in Fig. 3 (or Fig. S2 below) can be taken as an experimental evidence that the system does not fulfil detailed balance.

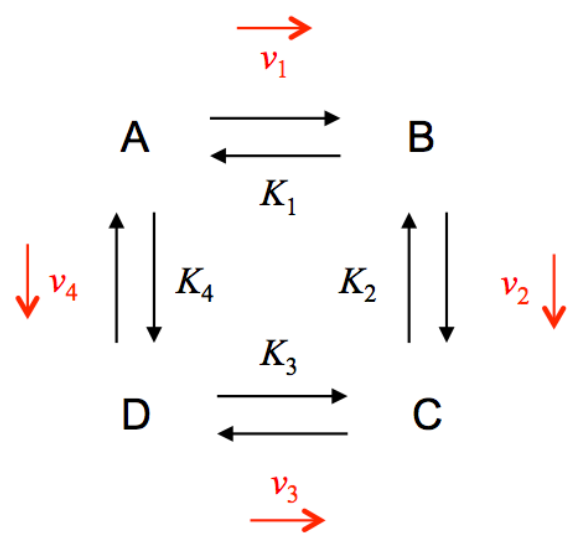

Supplementary Fig. 1. Square cycle consisting of four chemical equilibria. The indicated parameters refer to the reactions read from left to right and from top to bottom. Detailed balance states that, at equilibrium, all net rates are zero.

Kinetic modelling. The modelling of the kinetic behaviour of the system was performed by means of the SPECFIT software ${ }^{4}$. The mechanism used to simulate the experimental behaviour is depicted in Fig. S2 below and corresponds to that shown in Fig. 3.

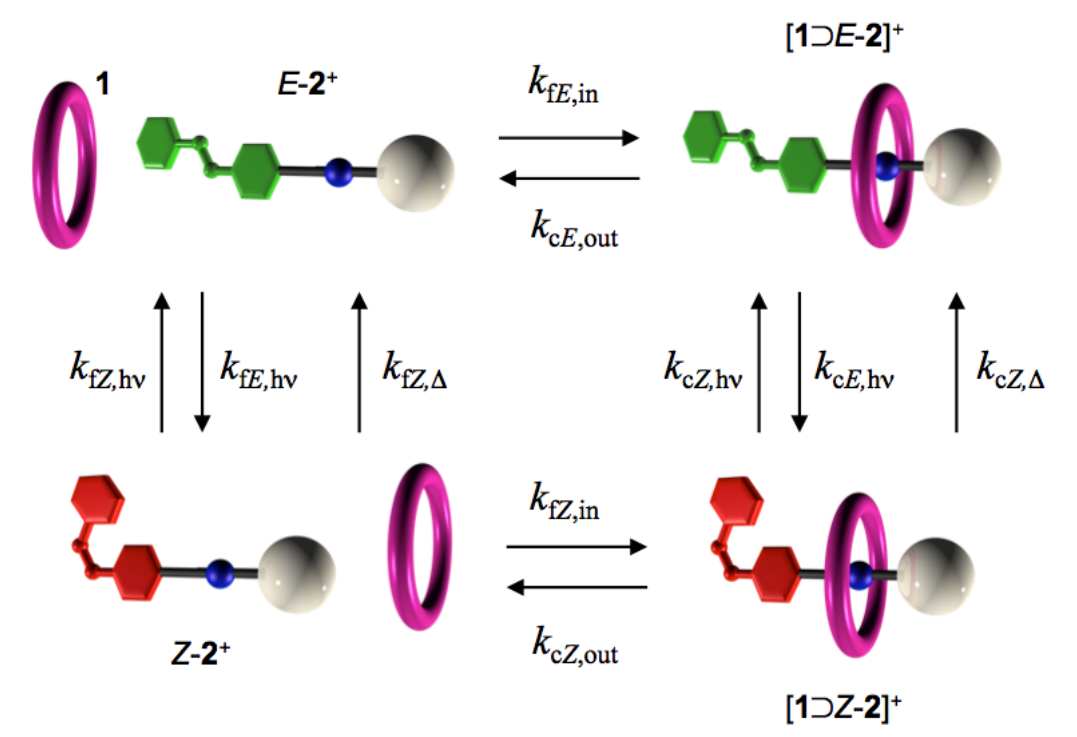

Supplementary Fig. 2. Kinetic scheme used to simulate the experimental behaviour. Photo and thermal $Z \rightarrow E$ isomerization processes - here shown as separate processes for clarity - will be modelled by a single cumulative rate constant (see text for details).

Indexes $\mathrm{f}$ and $\mathrm{c}$ denote free and complexed axles, respectively, whereas $\mathrm{h} v$ and $\Delta$ indicate photoisomerization and thermal isomerization reactions, respectively. The threading and dethreading processes are modelled as bimolecular and unimolecular processes, respectively; the 
corresponding rate constants are second-order $\left(k_{\text {in }}\right)$ and first-order $\left(k_{\text {out }}\right)$ constants. $Z \rightarrow E$ Thermal isomerization processes $(\Delta)$ are unimolecular processes. Under the employed experimental conditions (irradiation with monochromatic light and low absorbance at the irradiation wavelength), photoisomerization reactions $(\mathrm{h} v)$ can be treated as unimolecular processes. In fact, the photoisomerization quantum yield is expressed as:

$$
\Phi=-\frac{\Delta C V}{N_{\mathrm{h} v}}
$$

in which $\Delta C$ is the concentration change corresponding to the disappearance of the reactant (e.g., the $E$ form for the $E \rightarrow Z$ photoisomerization) in a given time interval, $V$ is the volume of the irradiated sample and $N_{\mathrm{h} v}$ is the number of photons absorbed by the reactant in the same time interval. Such a number is the product of the photon flow $\left(F_{\mathrm{h}_{\mathrm{v}}}\right)$, the fraction of light absorbed at the irradiation wavelength $\left(\mathfrak{I}_{\text {irr }}\right)$ and the time interval $(\Delta t)$ :

$$
N_{\mathrm{h} v}=F_{\mathrm{h} v} \mathfrak{\Im}_{\mathrm{irr}} \Delta t=F_{\mathrm{h} v}\left(1-10^{-A_{\text {irr }}}\right) \Delta t
$$

The exponential term in equation (S4) can be expanded and, if the absorbance at the irradiation wavelength is reasonably low (typically $<0.1$ ), orders higher than 1 can be neglected ${ }^{5}$. Hence,

$$
N_{\mathrm{h} v} \approx F_{\mathrm{h} v} A_{\mathrm{irr}} \Delta t=F_{\mathrm{h} v} \varepsilon_{\mathrm{irr}} b C \Delta t
$$

in which $\varepsilon_{\text {irr }}, b$ and $C$ are the molar absorption coefficient of the reactant at the irradiation wavelength, the optical path length and the reactant concentration. Substitution in equation (S3) yields equation (S6):

$$
\Phi=-\frac{\Delta C V}{F_{\mathrm{h} v} \varepsilon_{\mathrm{irr}} b C \Delta t}
$$

which, after rearrangement, results in equation (S7).

$$
-\frac{\Delta C}{\Delta t}=\frac{\Phi F_{\mathrm{h} v} \varepsilon_{\mathrm{irr}} b C}{V}=k C
$$


showing that the photoreaction obeys a first order kinetic law.

The values of the parameters related to chemical equilibria used in the simulation correspond to the experimental ones reported in Table 1 and Table S1. The apparent first-order rate constant for the $E \rightarrow Z$ photoisomerization processes of the free $\left(k_{\mathrm{f} E, \mathrm{~h}_{\mathrm{v}}}\right)$ and complexed $\left(k_{\mathrm{c} E, \mathrm{~h}^{\mathrm{v}}}\right)$ axles were estimated from the photoisomerization quantum yield (determined from photochemical experiments), the photon flow (Einstein $\mathrm{s}^{-1}$, measured by chemical actinometry), the molar absorption coefficient (determined from the absorption spectra), the irradiated volume $(3 \mathrm{~mL})$ and the optical path length $\left(1 \mathrm{~cm}\right.$ ), according to equation (S7). They resulted to be $k_{\mathrm{f} E \mathrm{~h} \mathrm{~h}^{\mathrm{v}}}=1.5 \times 10^{-3} \mathrm{~s}^{-1}$ and $k_{\mathrm{c} E, \mathrm{~h}^{\mathrm{h}}}=1.8 \times 10^{-3} \mathrm{~s}^{-1}$. Upon optimization of the fitting, the value of $k_{\mathrm{fE}, \mathrm{h}^{\mathrm{v}}}$ was adjusted to $1.6 \times 10^{-3} \mathrm{~s}^{-1}$ (well within experimental error). The cumulative apparent first-order rate constant of the $Z \rightarrow E$ photochemical and thermal isomerization processes (e.g., for the free axle, $k_{\mathrm{fZ}}=k_{Z, \mathrm{~h} v}+k_{\mathrm{fZ}, \text { ) }}$ ) were estimated from the composition of the photostationary state, taking advantage of equation (S8) valid at the PSS ${ }^{6}$ :

$\frac{\varepsilon_{E} \Phi_{E \rightarrow Z}}{\varepsilon_{Z} \Phi_{Z \rightarrow E}}=\frac{[Z]_{\mathrm{PSS}}}{[E]_{\mathrm{PSS}}}$

Combination with equation (S7) yields

$$
\begin{aligned}
& \frac{k_{\mathrm{f} E, \mathrm{~h} v}}{k_{\mathrm{f} Z}}=\frac{\left[Z-\mathbf{2}^{+}\right]_{\mathrm{PSS}}}{\left[E-\mathbf{2}^{+}\right]_{\mathrm{PSS}}} \\
& \frac{k_{\mathrm{c} E, \mathrm{~h} v}}{k_{\mathrm{c} Z}}=\frac{\left[\mathbf{1} \supset Z \mathbf{- 2}^{+}\right]_{\mathrm{PSS}}}{\left[\mathbf{1} \supset E-\mathbf{2}^{+}\right]_{\mathrm{PSS}}}
\end{aligned}
$$

The resulting upper limiting values are $k_{\mathrm{f} Z}<6.7 \times 10^{-5} \mathrm{~s}^{-1}$ and $k_{\mathrm{c} Z}<1.8 \times 10^{-5} \mathrm{~s}^{-1}$. The thermal $Z \rightarrow E$ isomerization rate constants reported in Table S1 are lower limiting values for the same processes. Upon optimization of the fitting the value of $k_{\mathrm{fZ}}$ was adjusted within the experimental error to $8.0 \times 10^{-5} \mathrm{~s}^{-1}$ and $k_{\mathrm{c} Z}$ was set equal to $1.8 \times 10^{-6} \mathrm{~s}^{-1}$.

The simulation presented in Fig. 4 was obtained in three steps. First $\mathbf{1}$ and $\mathrm{E-2}^{+}$were associated, without taking into account the equilibria involving light, i.e, the dark association of the components was simulated. Then, to reproduce the fast isomerization performed in the experiment, the obtained equilibrium concentrations for $E-2^{+}$and $[1 \supset E-2]^{+}$were mathematically converted to $96 \% Z$-isomer. Finally, the simulation was performed taking into account all the rate constants 
described above; the emission intensity was obtained normalizing the concentration of free ring for its equilibrium value after the initial association of $\mathbf{1}$ and $E-\mathbf{2}^{+}$.

Energetic considerations. The free energy change of the system upon performing directional cycling can be calculated from equation (S11), in which the partition constant $K$ is the ratio of the clockwise $\left(P_{\mathrm{cw}}\right)$ to counterclockwise $\left(P_{\mathrm{ccw}}\right)$ rates. This quantity corresponds to the maximum amount of energy that could in principle be converted into useful work. From the simulation of the experimental behaviour under our set of conditions we found that $P_{\mathrm{cw}} / P_{\mathrm{ccw}}=160$; thus, at $20^{\circ} \mathrm{C}$

$\Delta G=-R T \ln K=-R T \ln \frac{P_{\mathrm{cw}}}{P_{\mathrm{ccw}}}=-3.0 \mathrm{kcal} \mathrm{mol}^{-1}$

which corresponds to an energy of $5.1 k_{\mathrm{B}} T$. This result is identical to that calculated by using the generalized fluctuation-dissipation theorem for a closed reaction cycle coupled to an external energy source ${ }^{7,8}$.

Under the conditions employed, the cycling quantum yield is $2.3 \times 10^{-3}$ moles einstein ${ }^{-1}$, as calculated from equation (S12):

$\Phi_{c y c l}=\frac{N_{c y c l e s}}{N_{h v}}=\frac{v_{c y c l} \Delta t V}{F_{h v}\left(1-10^{-A_{\text {ir }}}\right) \Delta t}=2.3 \times 10^{-3}$

where the number of cycles $\left(N_{\text {cycles }}\right)$ performed in a given time interval $(\Delta t)$ is calculated from the cycling rate $\left(v_{\mathrm{cycl}}=1.7 \times 10^{-10} \mathrm{M} \mathrm{s}^{-1}\right)$ obtained from the kinetic simulation (see above). The number of photons absorbed $\left(N_{\mathrm{h}}\right)$ is given by equation (S3). It follows that, to perform a cycle under these conditions, ca. $1 / 2.3 \times 10^{-3} \approx 430$ photons of $365-\mathrm{nm}$ light $\left(78 \mathrm{kcal} \mathrm{mol}^{-1}\right)$ are needed on average. Therefore, the maximum energy conversion efficiency is

$\eta_{\max }=\frac{\Delta E_{\max }}{N h v}=\frac{3.0}{430 \times 78}=9 \times 10^{-5}$

These figures show that the system is able to exploit only a tiny fraction of the input light energy because, perhaps not surprisingly, most of the energy is wasted into heat in excited-state vibrational relaxation processes. 
a)

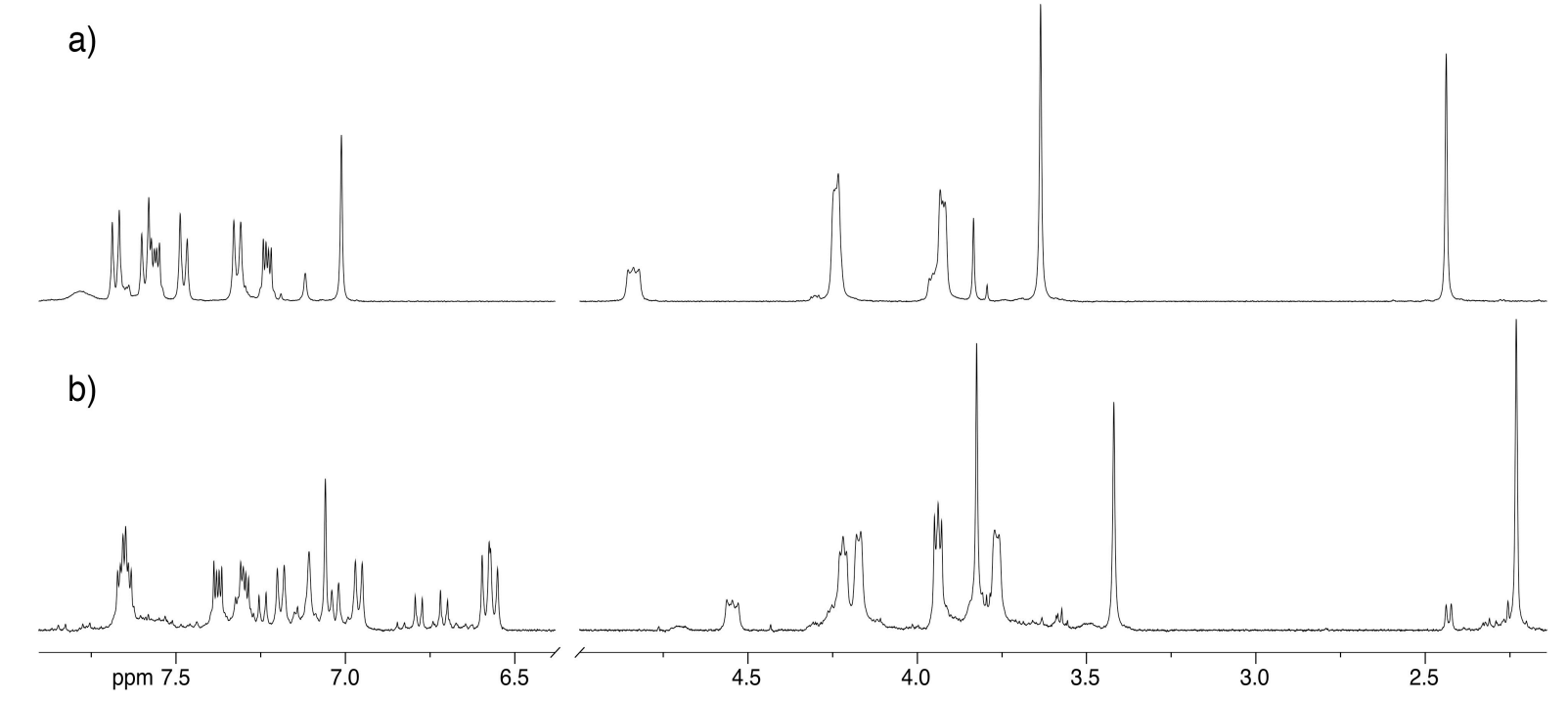

Supplementary Fig. 3. Partial ${ }^{1} \mathrm{H}$ NMR (400 MHz, $\mathrm{CD}_{2} \mathrm{Cl}_{2}, 298 \mathrm{~K}$ ) spectra of (a) a solution of 1 (3 mM) and $[E E-4] \mathrm{PF}_{6}(3 \mathrm{mM})$ and $(\mathrm{b})$ the same solution after exhaustive irradiation at $\lambda=365 \mathrm{~nm}$.

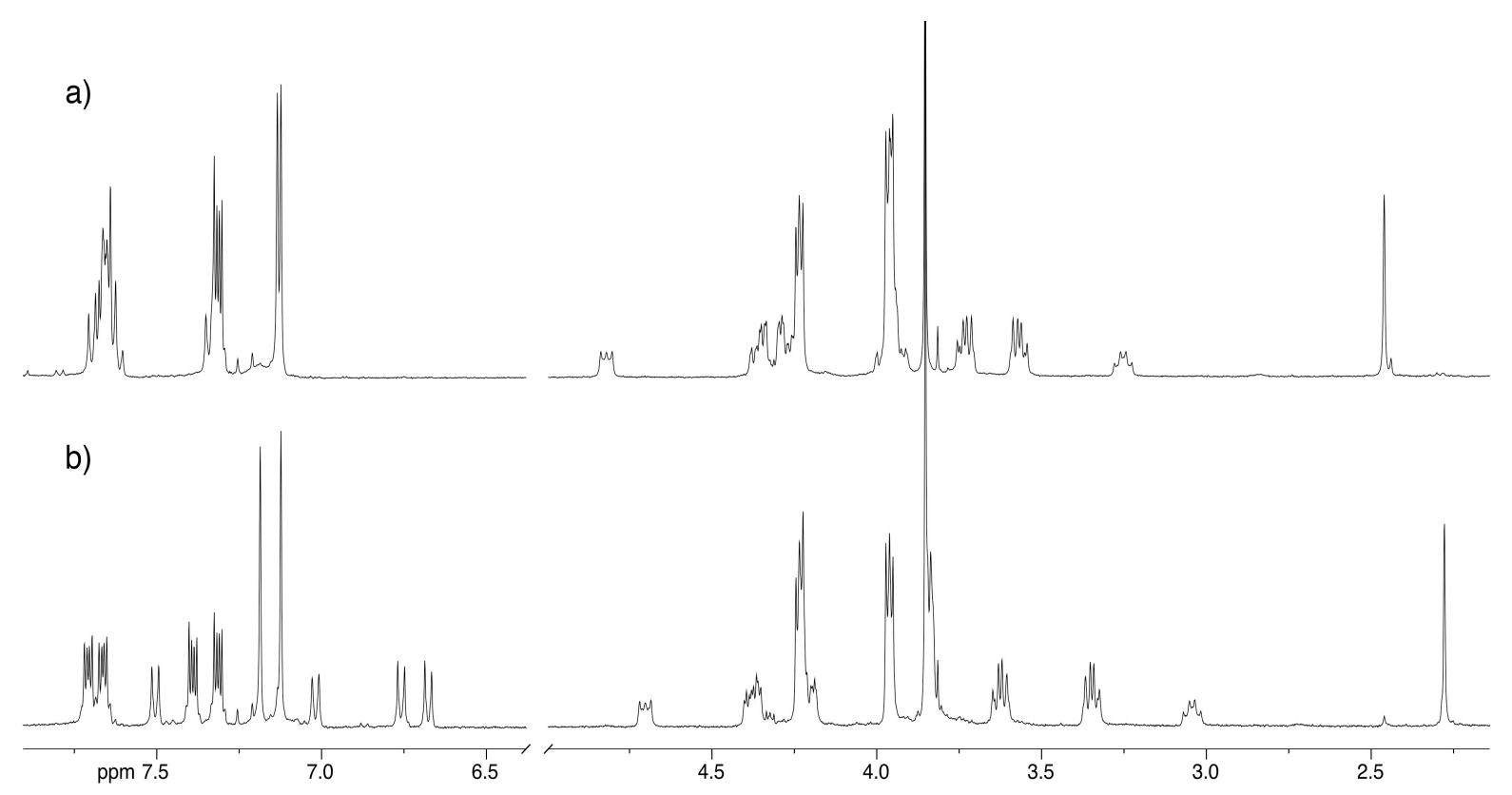

Supplementary Fig. 4. Partial ${ }^{1} \mathrm{H}$ NMR (400 MHz, $\left.\mathrm{CD}_{2} \mathrm{Cl}_{2}, 298 \mathrm{~K}\right)$ spectra of (a) a solution of 1 (3 mM) and $[E-2] \mathrm{PF}_{6}(3 \mathrm{mM})$ and $(\mathrm{b})$ the same solution after exhaustive irradiation at $\lambda=365 \mathrm{~nm}$. 


\section{UV-Visible Spectroscopy}

Supplementary Table 1. Spectroscopic and photochemical data of the investigated compounds $\left(\mathrm{CH}_{2} \mathrm{Cl}_{2}\right.$, r.t.).

\begin{tabular}{|c|c|c|c|c|c|c|c|c|}
\hline \multirow[t]{2}{*}{ Compound } & \multicolumn{2}{|c|}{ Absorption } & \multicolumn{3}{|c|}{ Luminescence } & \multicolumn{3}{|c|}{ Isomerization } \\
\hline & $\begin{array}{l}\lambda_{\max }, \\
\mathrm{nm}\end{array}$ & $\varepsilon, \mathrm{M}^{-1} \mathrm{~cm}^{-1}$ & $\begin{array}{l}\lambda_{\max }, \\
\mathrm{nm}\end{array}$ & $\Phi_{\mathrm{em}}$ & $\tau, \mathrm{ns}$ & $\begin{array}{l}\Phi_{E-Z}\left(\lambda_{\text {irr, }}\right. \\
\mathrm{nm})\end{array}$ & $\begin{array}{l}Z / E \text { PSS, \% } \\
\left(\lambda_{\text {irr }}, \mathrm{nm}\right)\end{array}$ & $k_{Z, \wedge}, \mathrm{s}^{-1}$ \\
\hline 1 & $\begin{array}{l}268 \\
324\end{array}$ & $\begin{array}{l}9500 \\
7900\end{array}$ & 343 & 0.26 & 9.8 & - & - & - \\
\hline$E-2^{+}$ & $\begin{array}{l}332 \\
448\end{array}$ & $\begin{array}{l}23000 \\
700\end{array}$ & [a] & [a] & [a] & $\begin{array}{l}0.15(365) \\
0.30(346) \\
0.15(287)\end{array}$ & $>96(365)$ & - \\
\hline$[1 \supset E-2]^{+}$ & $\begin{array}{l}323 \\
448\end{array}$ & $\begin{array}{l}30000 \\
700\end{array}$ & - & $<10^{-4}$ & - & $\begin{array}{l}0.15(365) \\
0.30(436) \\
0.15(287)\end{array}$ & $>99(365)$ & - \\
\hline$Z-2^{+}$ & $\begin{array}{l}287 \\
437\end{array}$ & $\begin{array}{l}5500 \\
1700\end{array}$ & [a] & [a] & [a] & - & - & $1.4 \times 10^{-6[b]}$ \\
\hline$[1 \supset Z-2]^{+}$ & $\begin{array}{l}323 \\
437\end{array}$ & $\begin{array}{l}9400 \\
1700\end{array}$ & - & $<10^{-4}$ & - & - & - & $1.3 \times 10^{-6[b]}$ \\
\hline $3^{+}$ & [c] & {$[\mathrm{c}]$} & [a] & [a] & [a] & - & - & - \\
\hline$[\mathbf{1} \supset \mathbf{3}]^{+}$ & $\begin{array}{l}268 \\
322\end{array}$ & $\begin{array}{l}9800 \\
7600\end{array}$ & 343 & 0.26 & - & - & - & - \\
\hline$E E-4^{+}$ & $\begin{array}{l}335 \\
441\end{array}$ & $\begin{array}{l}43000 \\
1200\end{array}$ & [a] & [a] & [a] & $0.15(365)$ & $>96(365)^{[\mathrm{d}]}$ & - \\
\hline$[\mathbf{1} \supset E E-\mathbf{4}]^{+}$ & $\begin{array}{l}323 \\
441\end{array}$ & $\begin{array}{l}46000 \\
1200\end{array}$ & - & $<10^{-4}$ & - & $\begin{array}{l}0.15(365) \\
0.15(287)\end{array}$ & $>96(365)^{[\mathrm{d}]}$ & - \\
\hline$Z Z-4^{+}$ & $\begin{array}{l}289 \\
436\end{array}$ & $\begin{array}{l}10000 \\
2900\end{array}$ & [a] & [a] & [a] & - & - & $4 \times 10^{-6[b]}$ \\
\hline$[1 \supset Z Z-4]^{+}$ & - & - & - & $<10^{-4}$ & - & - & - & - \\
\hline
\end{tabular}

[a] Not luminescent.

[b] Performed at $20^{\circ} \mathrm{C}$.

[c] The compound does not absorb in the investigated spectral region $(250-800 \mathrm{~nm})$.

[d] According to a statistical distribution of the $E$ and $Z$ azobenzene units, the composition of the PSS in terms of the various isomeric forms is $92 \% \mathrm{ZZ}, 8 \% \mathrm{EZ}$ and a negligible amount of $E E$. 
Supplementary Table 2. Composition of the photostationary state for the free and complexed axle $\mathbf{2}$ under different irradiation conditions, determined from the disappearance of the $\pi \pi^{*}$ absorption band of the azobenzene unit of the axle.

\begin{tabular}{ccc}
\hline$\lambda_{\text {irr }}(\mathrm{nm})$ & $Z-\mathbf{2}^{+}(\%)$ & {$[\mathbf{1} \supset Z-\mathbf{2}]^{+}(\%)$} \\
\hline 287 & 24 & 31 \\
365 & 96 & $>99$ \\
436 & 16 & 16 \\
\hline
\end{tabular}




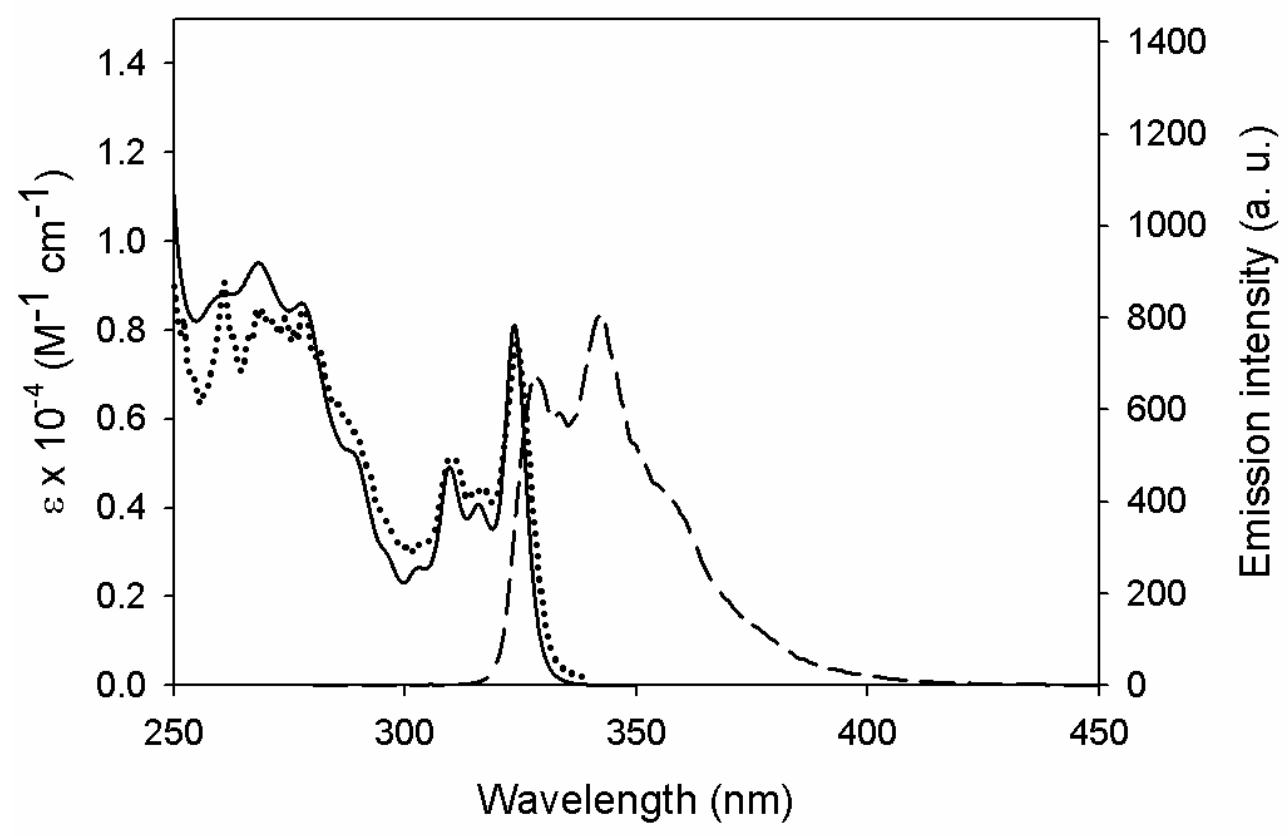

Supplementary Fig. 5. Absorption (full line, left scale) and luminescence (right scale) emission (dashed line, $\lambda_{\text {exc }}=272 \mathrm{~nm}$ ) and excitation (dotted line, $\lambda_{\max }=345 \mathrm{~nm}$ ) spectra of macrocycle $\mathbf{1}$ (air equilibrated $\mathrm{CH}_{2} \mathrm{Cl}_{2}$, r.t.).

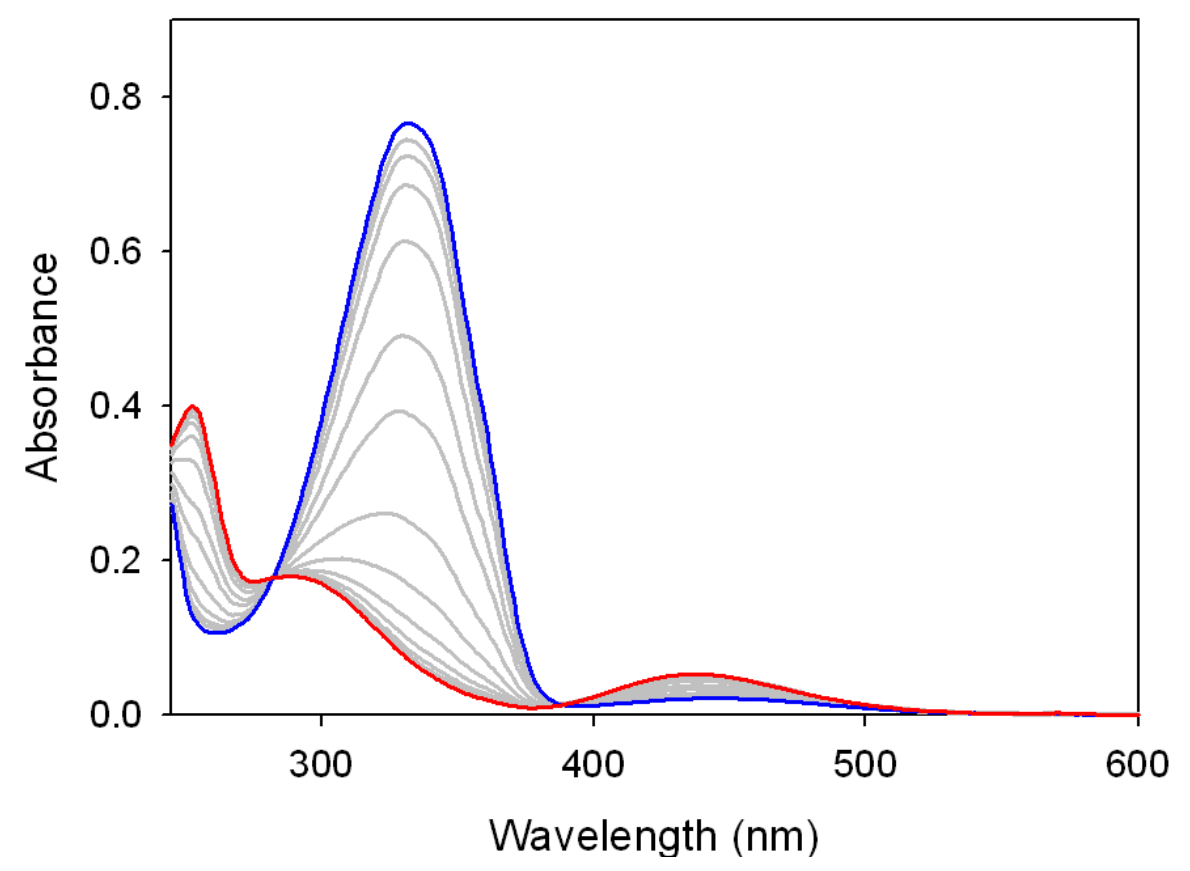

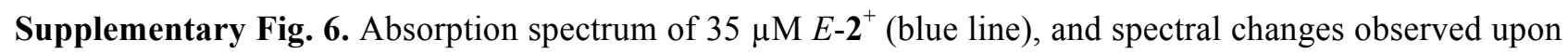
irradiation of the solution at $365 \mathrm{~nm}$, showing the occurrence of the $E \rightarrow Z$ photoisomerization $\left(\mathrm{CH}_{2} \mathrm{Cl}_{2}\right.$, r.t.). The red line shows the absorption spectrum of $Z_{-2}^{+}$. 


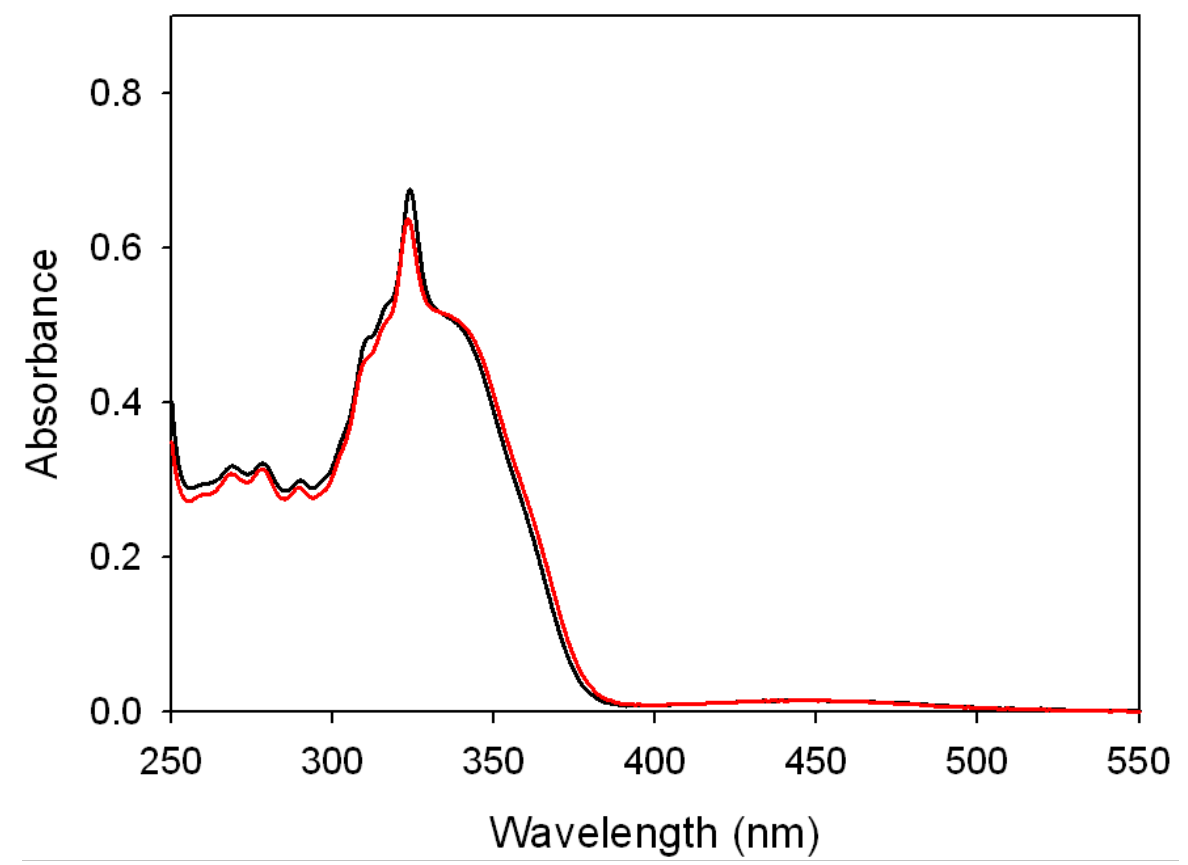

Supplementary Fig. 7. Sum of the absorption spectra of $20 \mu \mathrm{M} 1$ and $E-\mathbf{2}^{+}$(black line), and absorption spectrum of the mixture of the two compounds (red line) at the same concentration $\left(\mathrm{CH}_{2} \mathrm{Cl}_{2}\right.$, r.t.). Dedicated spectrophotometric cells with separated compartments allowed a careful in situ determination of the spectra of unmixed and mixed solutions.

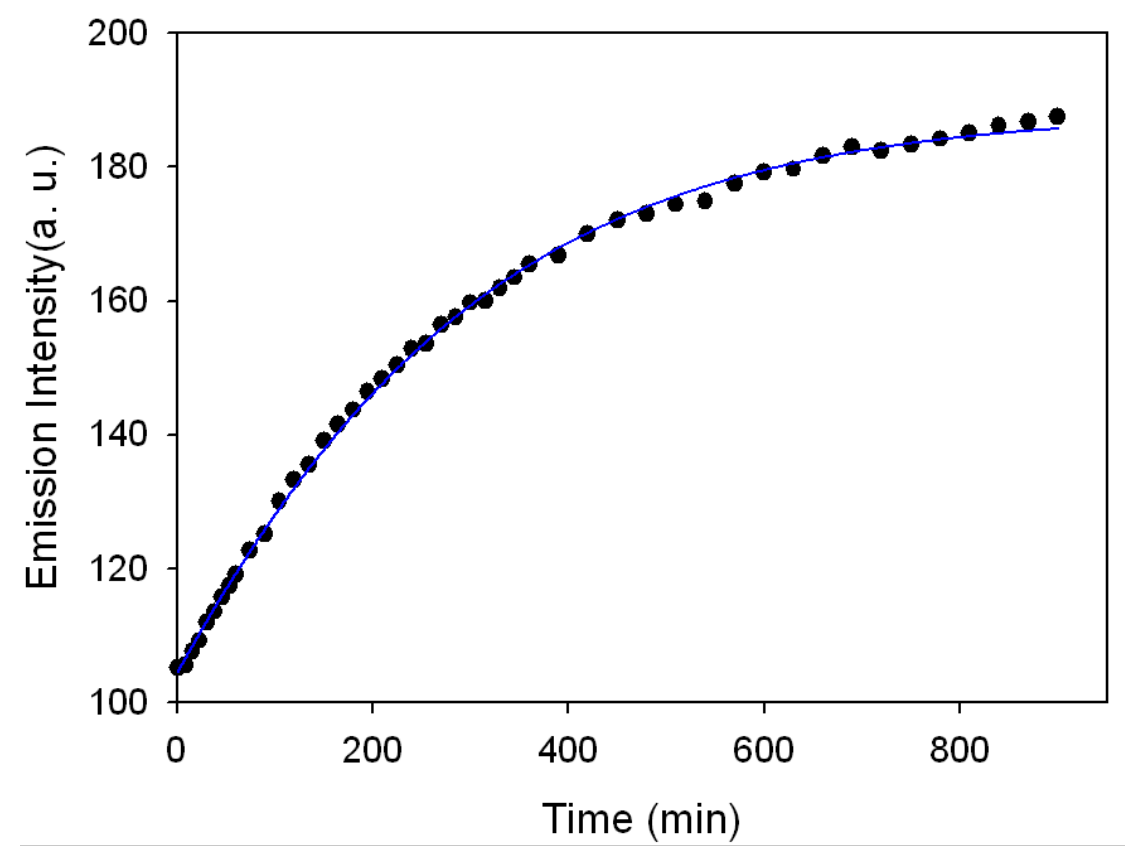

Supplementary Fig. 8. Observation of the dethreading of $[1 \supset E-2]^{+}$. Time-dependent luminescence changes $\left(\lambda_{\mathrm{exc}}=272 \mathrm{~nm}, \lambda_{\mathrm{em}}=390 \mathrm{~nm}\right)$ upon 20 -fold dilution of a solution of $75 \mu \mathrm{M} 1$ and $E-\mathbf{2}^{+}(86 \%$ initial complexation) in $\mathrm{CH}_{2} \mathrm{Cl}_{2}$ at $20^{\circ} \mathrm{C}$. The full line is the data fit according to a first-order kinetic equation. 


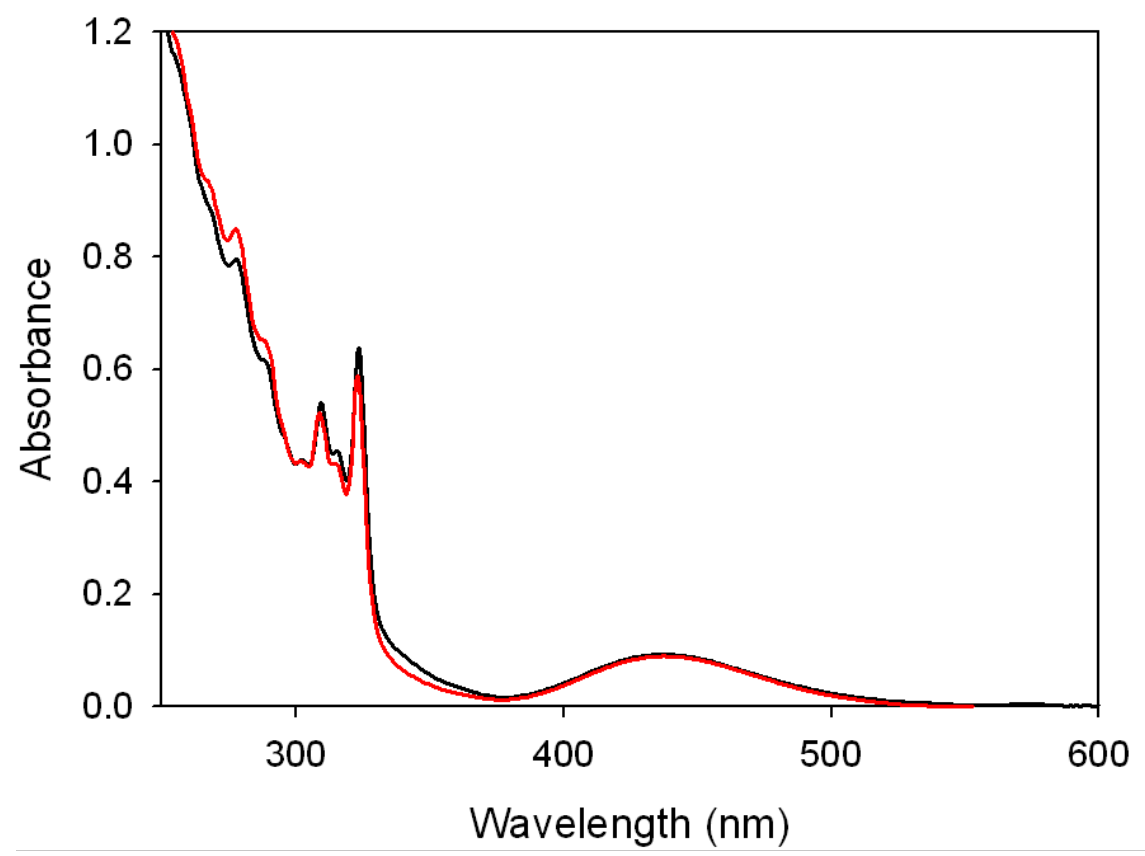

Supplementary Fig. 9. Sum of the absorption spectra of $60 \mu \mathrm{M} 1$ and Z-2 ${ }^{+}$(black line), and absorption spectrum of the mixture of the two compounds at the same concentration $\left(\mathrm{CH}_{2} \mathrm{Cl}_{2}\right.$, r.t.). The sum of the absorption spectra is obtained mathematically from the molar absorption coefficient of the two components, the absorption spectrum of the mixture is obtained upon exhaustive irradiation ( $365 \mathrm{~nm}$ ) of an equilibrated mixture of 1 and $Z-\mathbf{2}^{+}$.

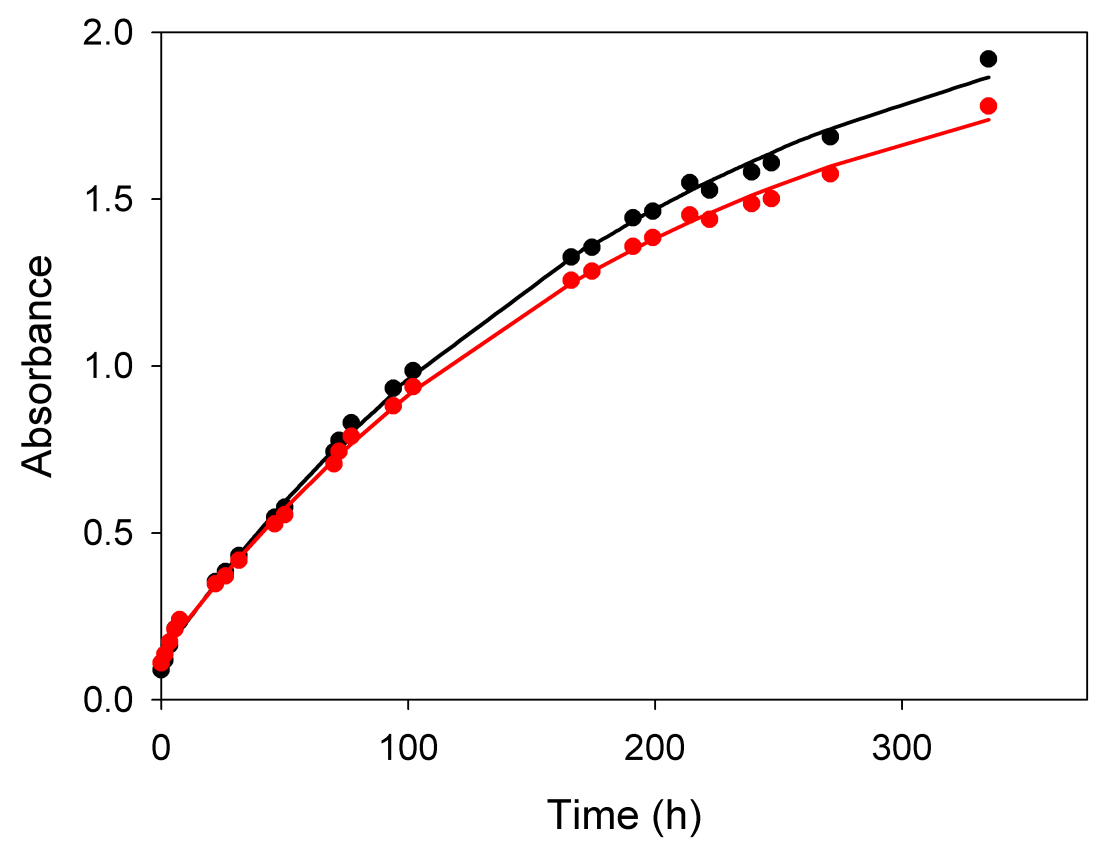

Supplementary Fig. 10. Time-dependent absorption changes at $340 \mathrm{~nm}$ observed on a $150 \mu \mathrm{M} \mathrm{CH}_{2} \mathrm{Cl}_{2}$ solution of $\mathrm{Z-2}^{+}$alone (red circles) and in the presence of $150 \mu \mathrm{M} 1$ (black circles) in the dark at $20{ }^{\circ} \mathrm{C}$, highlighting the occurrence of the $Z \rightarrow E$ thermal isomerization. The lines are the data fitting according to a first-order kinetic equation. 


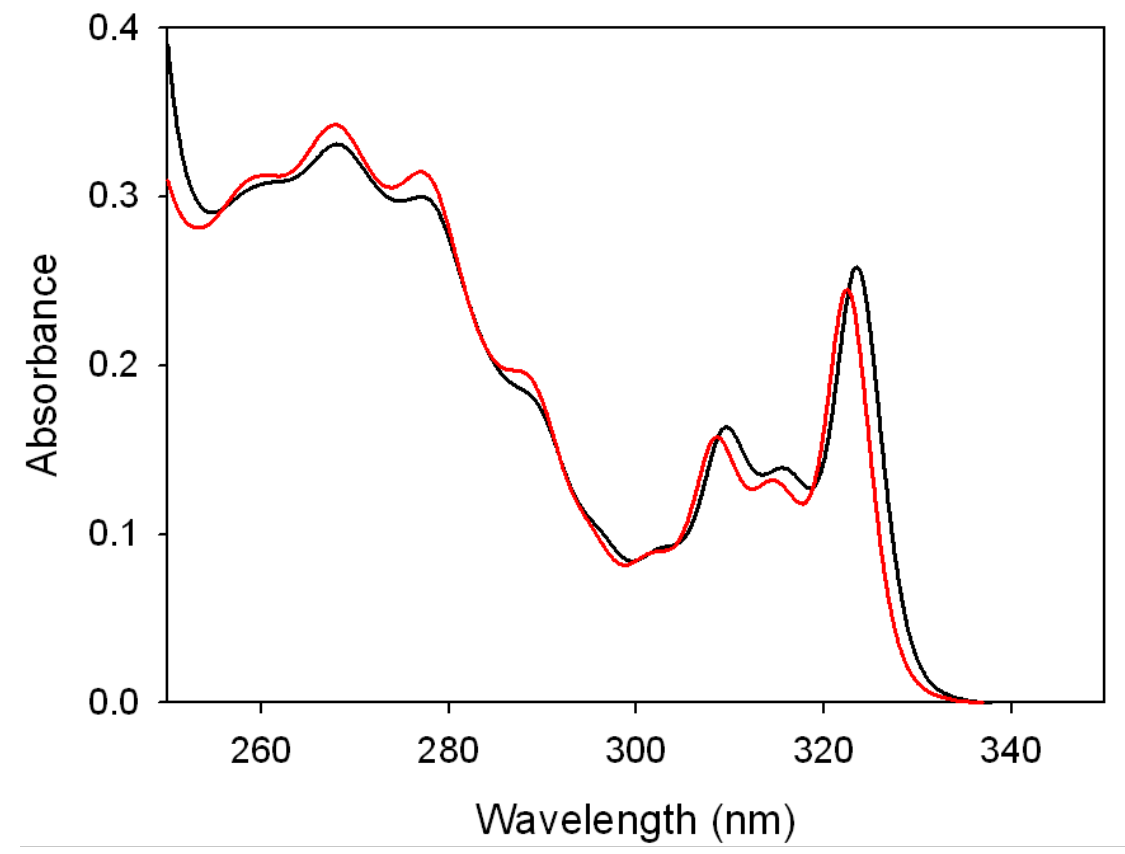

Supplementary Fig. 11. Sum of the absorption spectra of $30 \mu \mathrm{M} 1$ and a $1.0 \mathrm{mM} \mathrm{3}^{+}$(black line), and absorption spectrum of the mixture of the two compounds at the same concentration $\left(\mathrm{CH}_{2} \mathrm{Cl}_{2}\right.$, r.t.). Dedicated spectrophotometric cells with separated compartments allowed a careful in situ determination of the spectra of unmixed and mixed solutions.

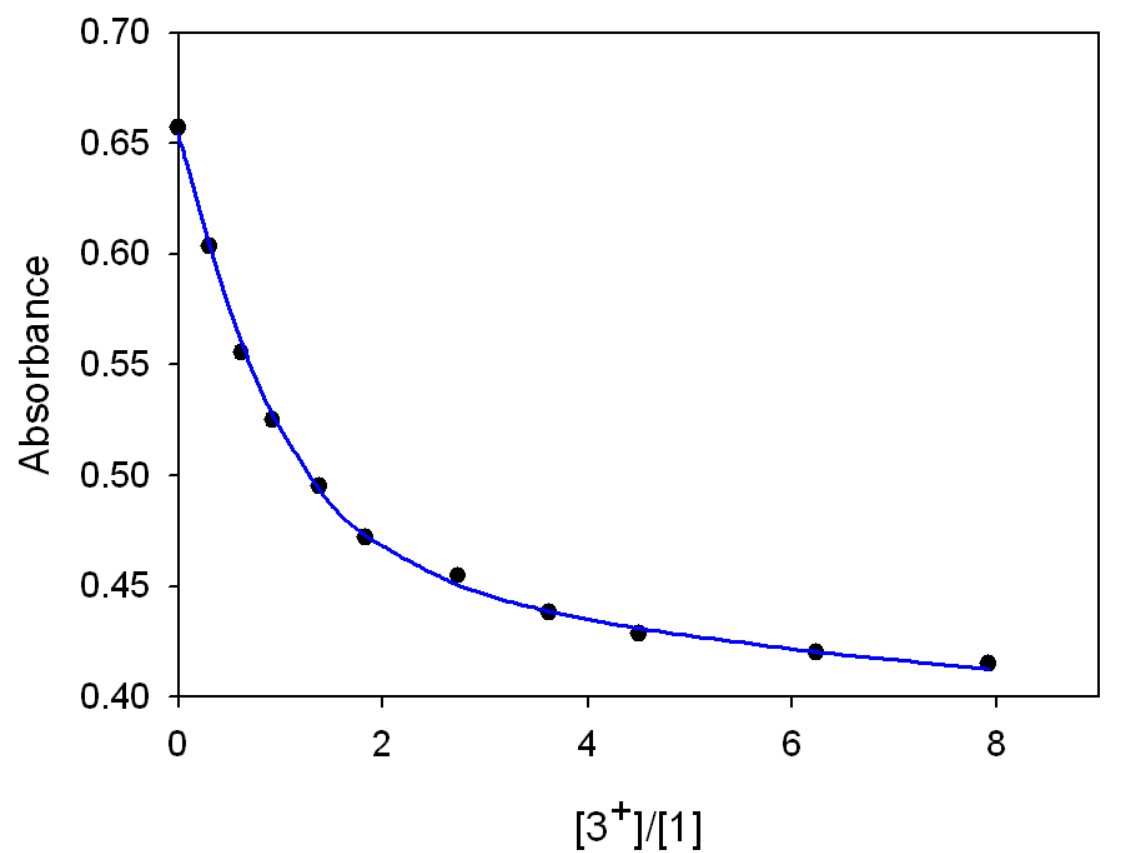

Supplementary Fig. 12. Titration curve, obtained from the absorbance values at $325 \mathrm{~nm}$, observed upon addition of $3^{+}$to a $80 \mu \mathrm{M}$ solution of 1 in $\mathrm{CH}_{2} \mathrm{Cl}_{2}$ at $20{ }^{\circ} \mathrm{C}$. The full line represents the data fitting according to a $1: 1$ binding model. 


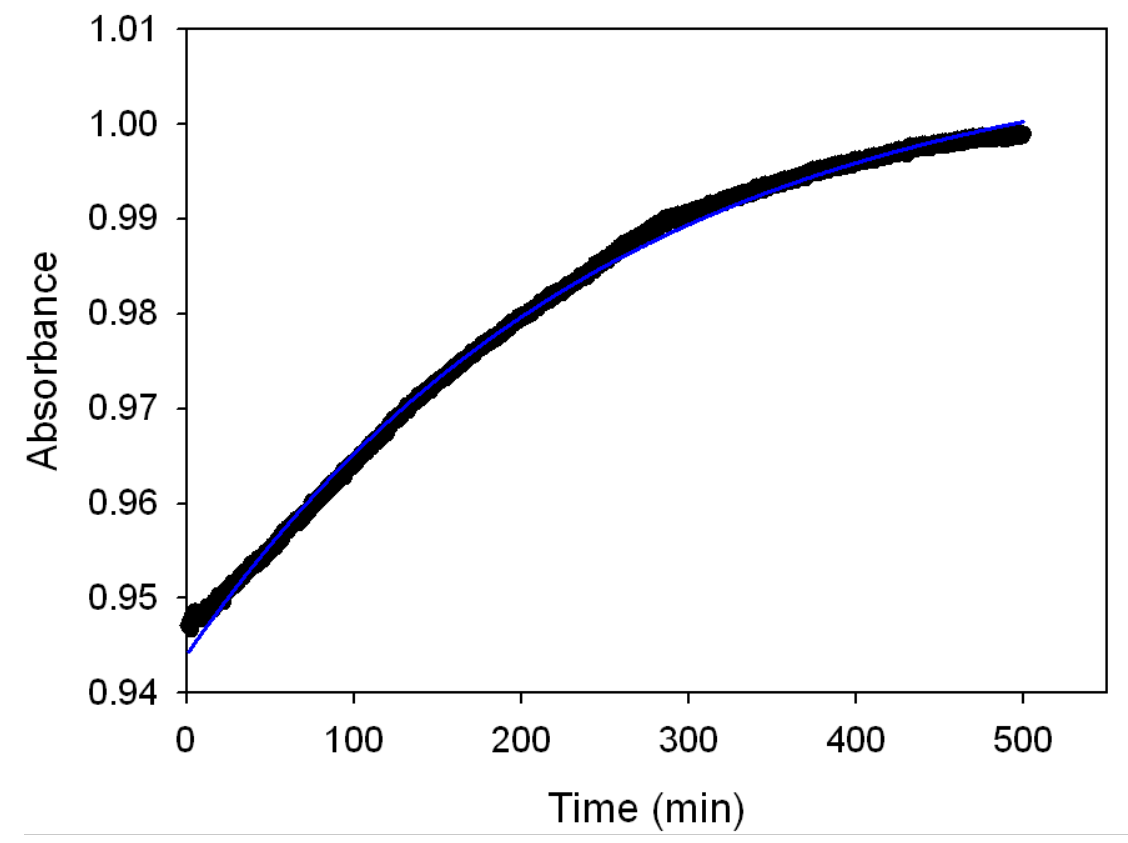

Supplementary Fig. 13. Observation of the dethreading of $[\mathbf{1} \supset \mathbf{3}]^{+}$. Time-dependent absorbance changes at $325 \mathrm{~nm}$ upon 6-fold dilution of a solution of $175 \mu \mathrm{M} \mathbf{1}$ and $\mathbf{3}^{+}$(66\% initial complexation) in $\mathrm{CH}_{2} \mathrm{Cl}_{2}$ at $20{ }^{\circ} \mathrm{C}$. The full line is the data fit according to a first-order kinetic equation. To enhance the increase in the absorbance $5 \mathrm{~cm}$ pathlength cuvettes were used in this experiment.

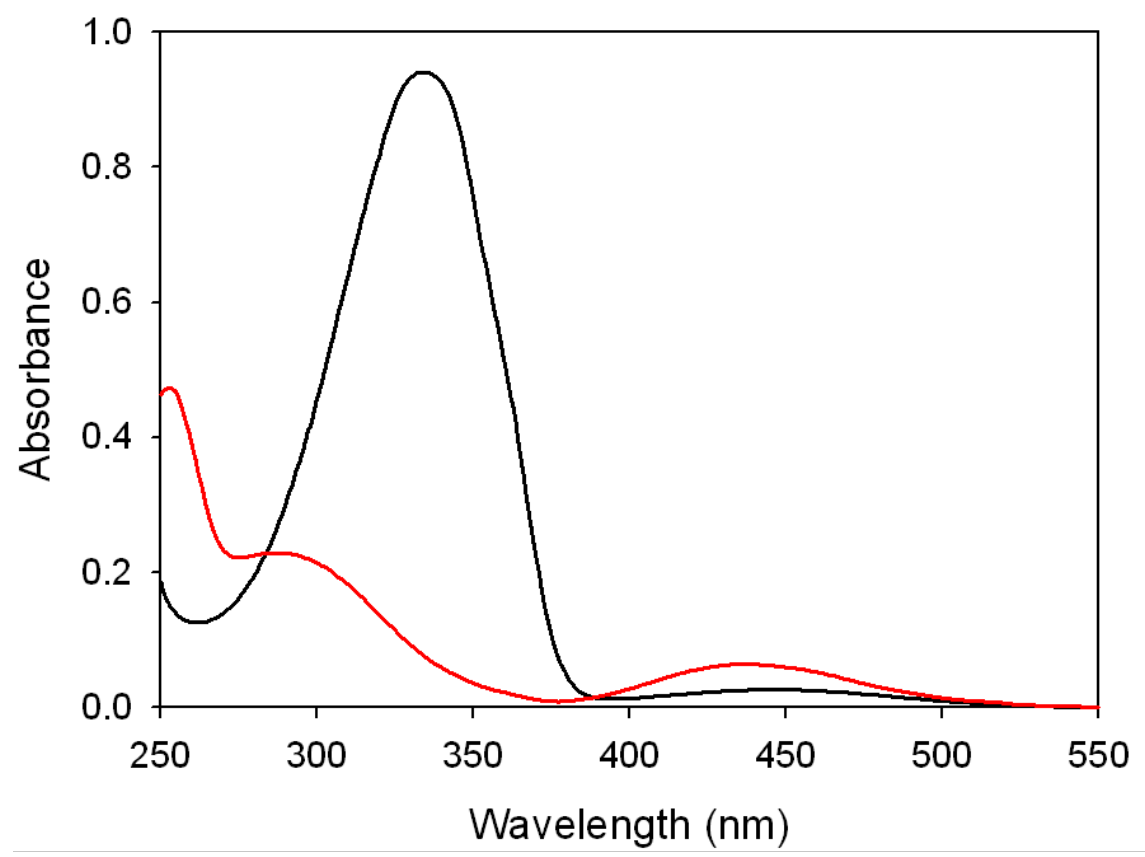

Supplementary Fig. 14. Absorption spectrum of $22 \mu \mathrm{M} E E-4^{+}$(blue line), and absorption spectrum of ZZ-4 (red line), obtained upon exhaustive irradiation of the solution at $365 \mathrm{~nm}\left(\mathrm{CH}_{2} \mathrm{Cl}_{2}\right.$, r.t.). 


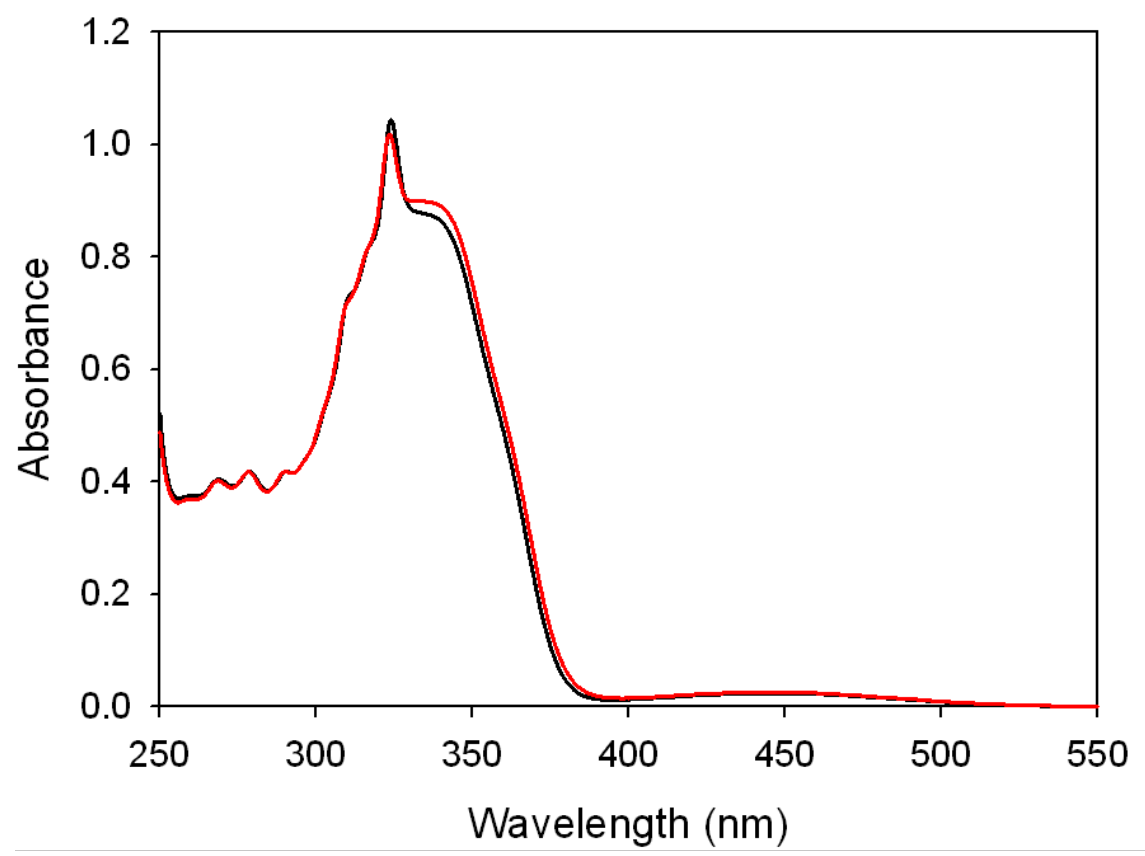

Supplementary Fig. 15. Sum of the absorption spectra of $20 \mu \mathrm{M} 1$ and $E-\mathbf{4}^{+}$(black line), and absorption spectrum of the mixture of the two compounds at the same concentration $\left(\mathrm{CH}_{2} \mathrm{Cl}_{2}\right.$, r.t.). Dedicated spectrophotometric cells with separated compartments allowed a careful in situ determination of the spectra of unmixed and mixed solutions.

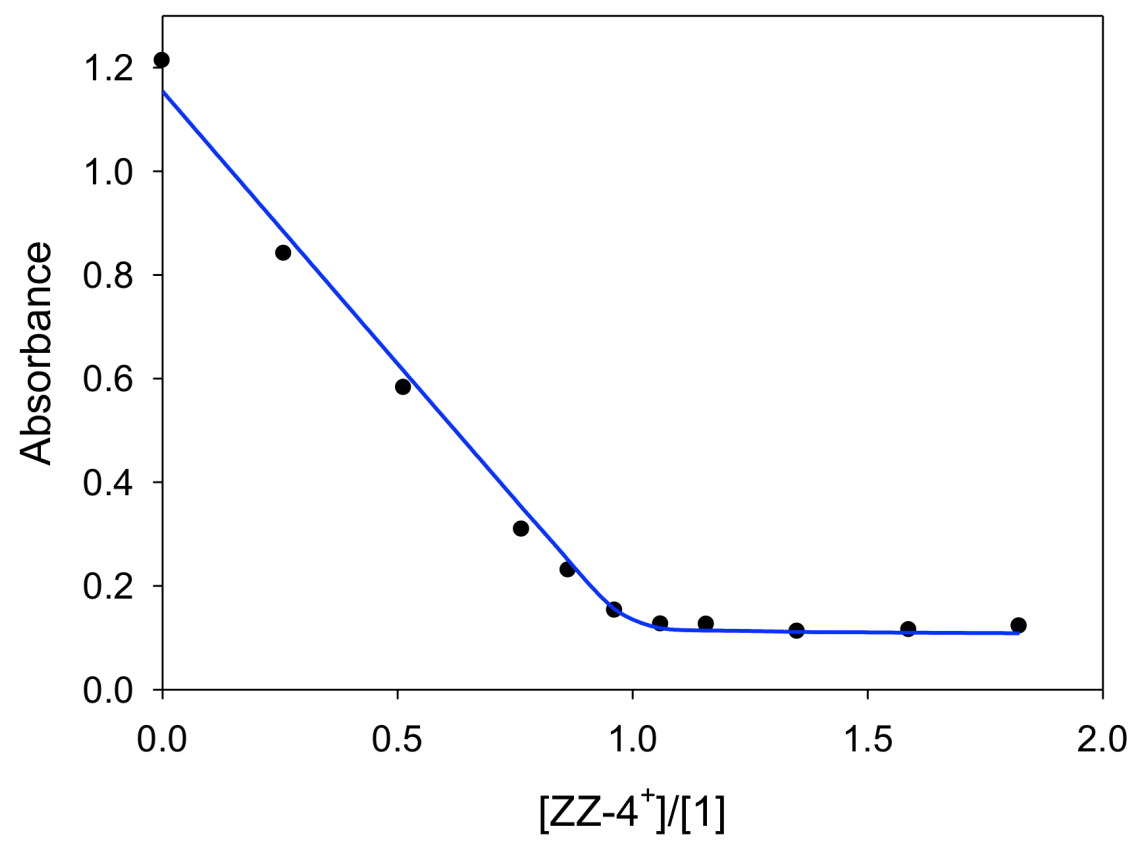

Supplementary Fig. 16. Titration curve, obtained from emission intensity values $\left(\lambda_{\text {exc }}=282 \mathrm{~nm}, \lambda_{\text {em }}=390\right.$ $\mathrm{nm}$ ), observed upon addition of $E E-4^{+}$to a $50 \mu \mathrm{M}$ solution of $\mathbf{1}$ in $\mathrm{CH}_{2} \mathrm{Cl}_{2}$ at $20^{\circ} \mathrm{C}$. The full line represents the data fitting according to a 1:1 binding model. 


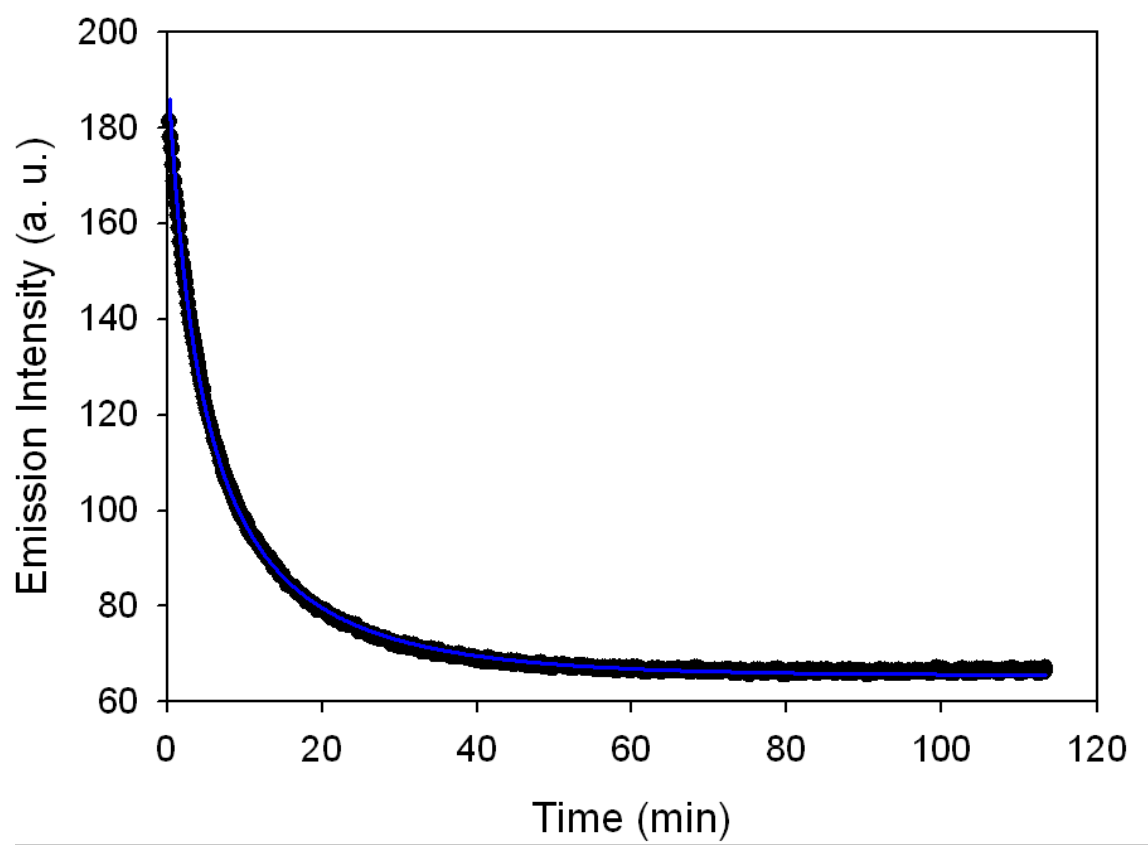

Supplementary Fig. 17. Time-dependent luminescence changes $\left(\lambda_{\mathrm{exc}}=282 \mathrm{~nm}, \lambda_{\mathrm{em}}=390 \mathrm{~nm}\right)$ observed upon mixing $100 \mu \mathrm{M} 1$ with $100 \mu \mathrm{M} \mathrm{EE-4}{ }^{+}$in $\mathrm{CH}_{2} \mathrm{Cl}_{2}$ at $20{ }^{\circ} \mathrm{C}$. The full line represents the data fitting according to a kinetic model consisting of a second-order threading and an opposed first-order dethreading.

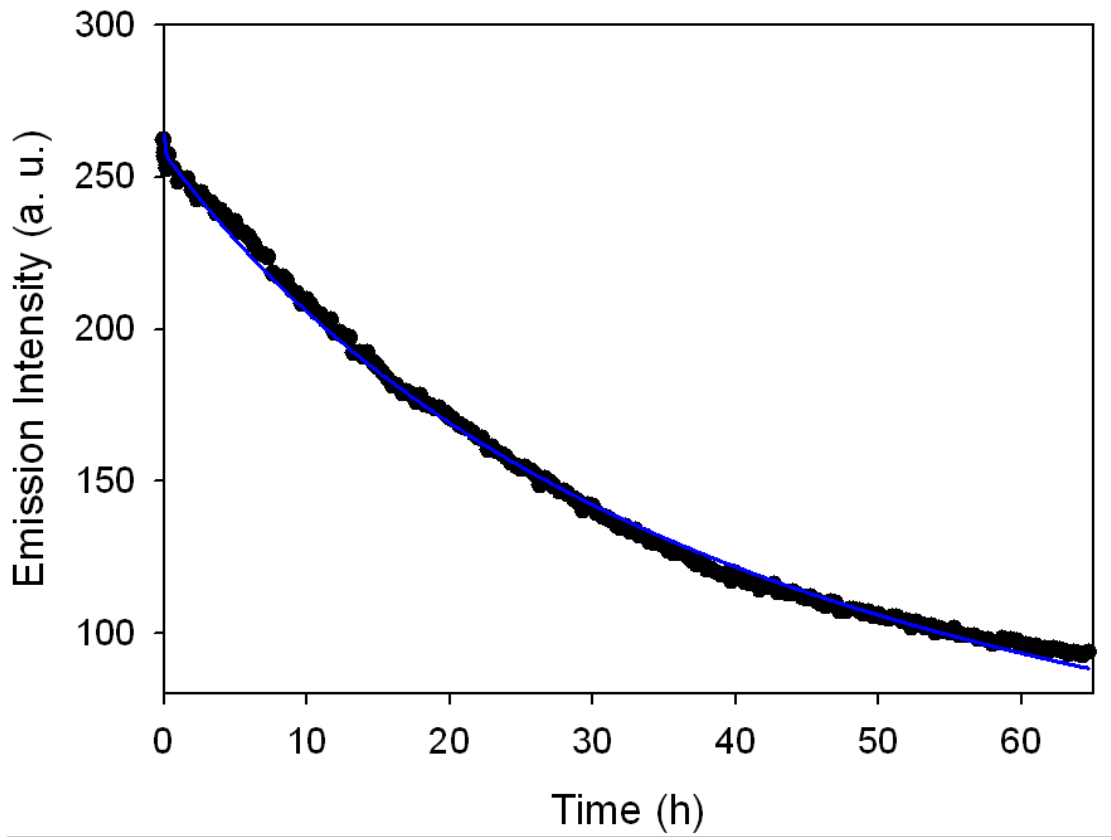

Supplementary Fig. 18. Time-dependent luminescence changes $\left(\lambda_{\mathrm{exc}}=282 \mathrm{~nm}, \lambda_{\mathrm{em}}=390 \mathrm{~nm}\right)$ observed upon mixing $100 \mu \mathrm{M} 1$ with $100 \mu \mathrm{M} \mathrm{ZZ-4}{ }^{+}$in $\mathrm{CH}_{2} \mathrm{Cl}_{2}$ at $20{ }^{\circ} \mathrm{C}$. The full line represents the data fitting according to a kinetic model consisting of a second-order threading and opposed first-order dethreading and $Z \rightarrow E$ isomerization. 


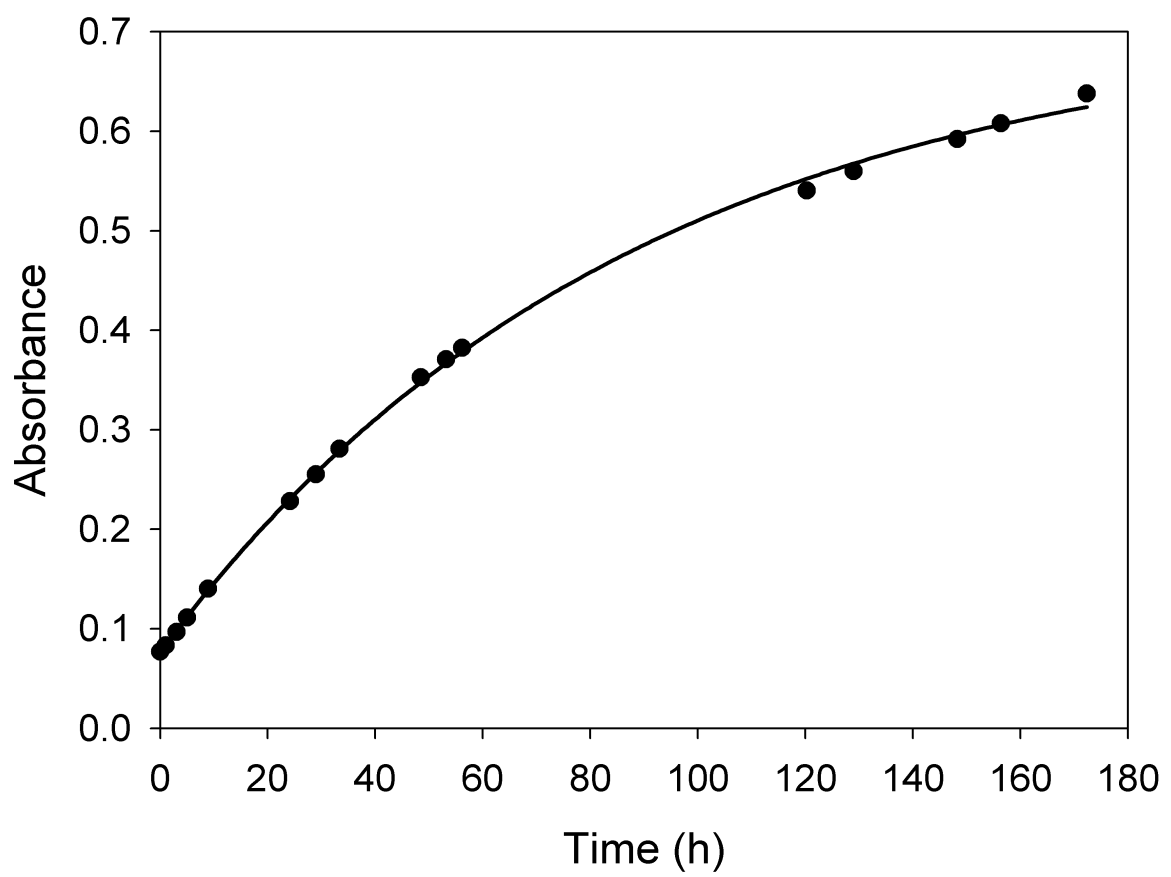

Supplementary Fig. 19. Time-dependent absorption changes at $340 \mathrm{~nm}$ observed on a $20 \mu \mathrm{M} \mathrm{CH}_{2} \mathrm{Cl}_{2}$ solution of $Z Z-4^{+}$alone (green circles) in the dark at $20{ }^{\circ} \mathrm{C}$, highlighting the occurrence of the $Z \rightarrow E$ thermal isomerization. The line is the data fitting according to a first-order kinetic equation.

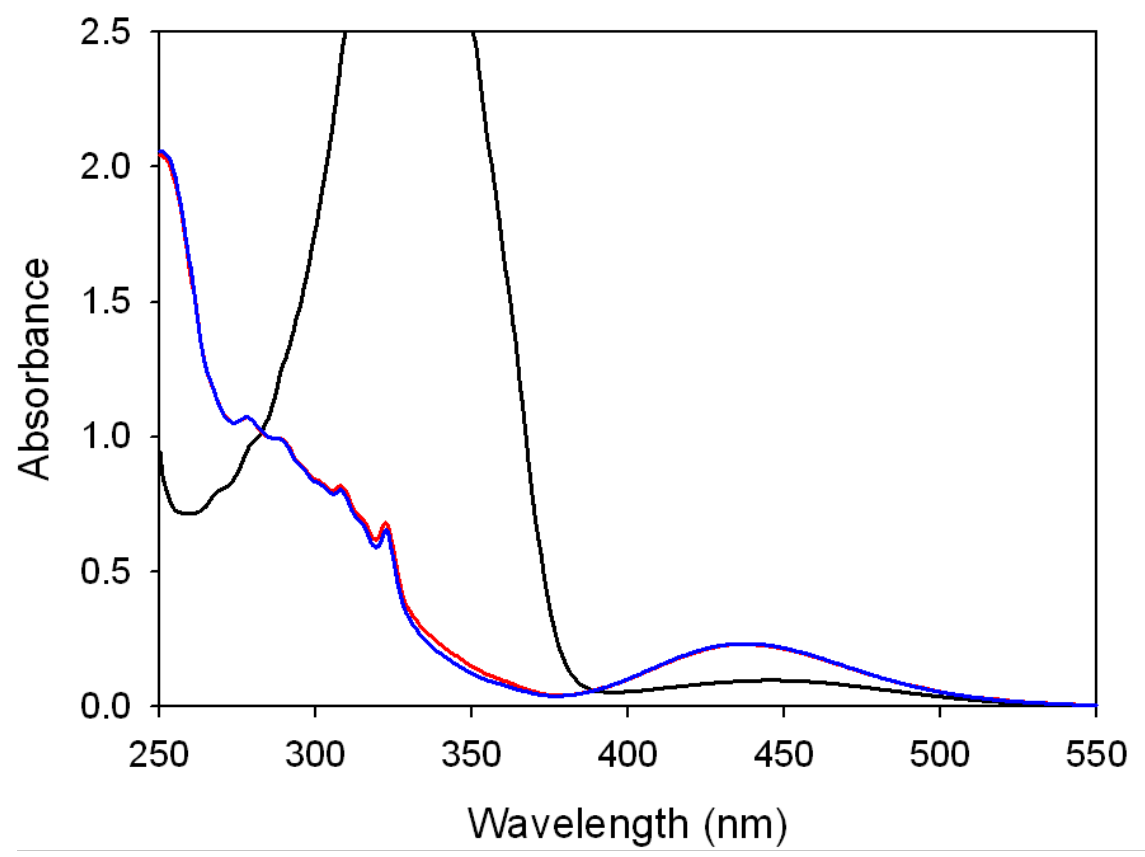

Supplementary Fig. 20. Absorption spectra corresponding to the luminescence data presented in Figure 4.

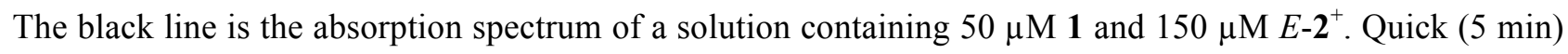
exhaustive irradiation of this solution at $365 \mathrm{~nm}$ generates the spectrum shown as the red line. The blue line is the absorption spectrum after prolonged $(3.5 \mathrm{~h})$ low-intensity $365-\mathrm{nm}$ irradiation of the same solution. The absorption spectra recorded at intermediate irradiation times are all superimposed with the blue line and are omitted for clarity. 


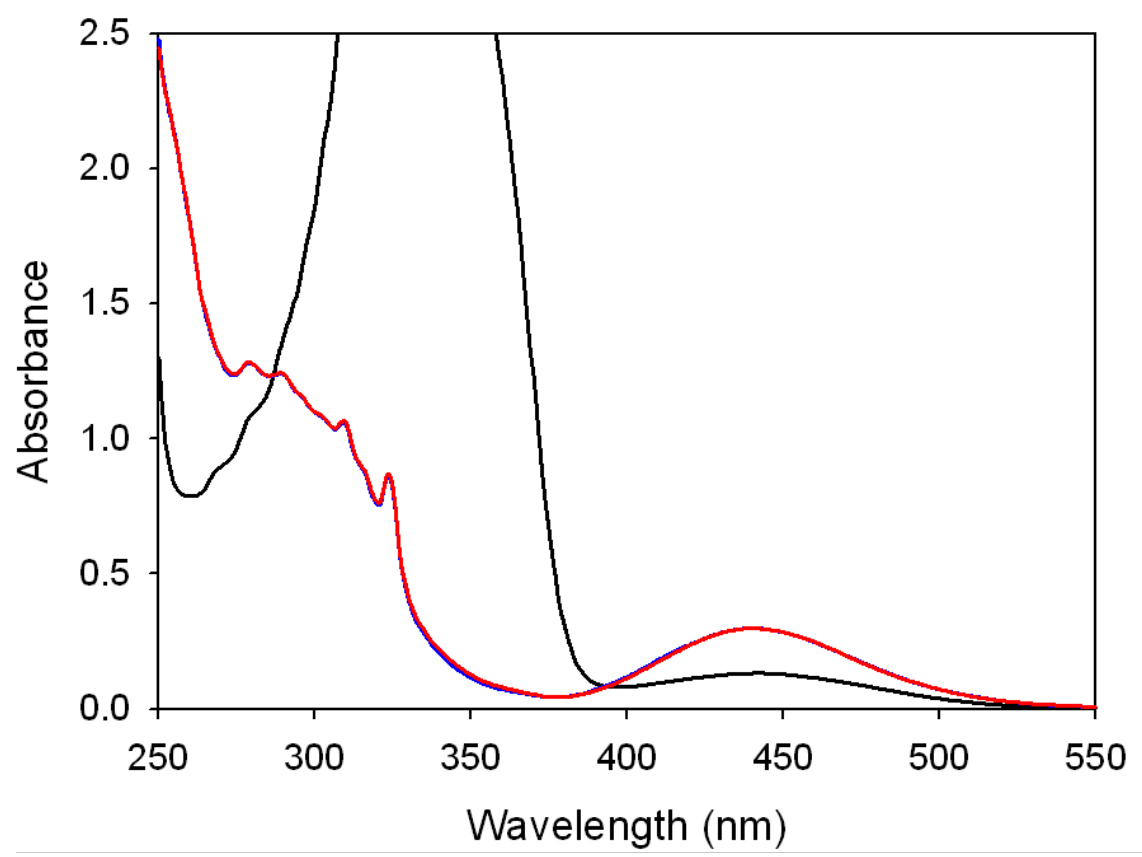

Supplementary Fig. 21. Absorption spectra corresponding to the luminescence data presented in Figure 4 (control experiment). The black line is the absorption spectrum of a solution containing $50 \mu \mathrm{M} 1$ and 150 $\mu \mathrm{M}$ deprotonated axle $E$-2. Quick ( $5 \mathrm{~min}$ ) exhaustive irradiation of this solution at $365 \mathrm{~nm}$ generates the spectrum shown as the red line. The blue line is the absorption spectrum after prolonged $(3.5 \mathrm{~h})$ low-intensity $365-\mathrm{nm}$ irradiation of the same solution. The absorption spectra recorded at intermediate irradiation times are all superimposed with the blue line and are omitted for clarity.

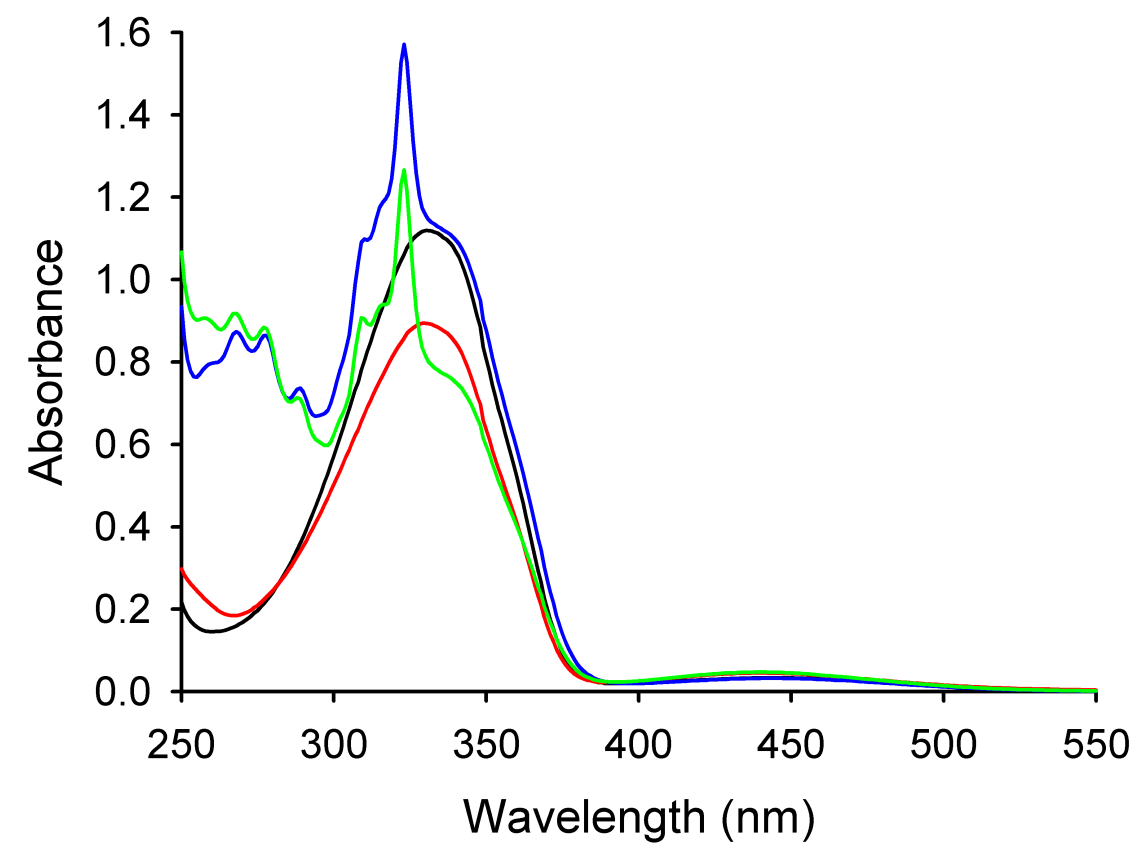

Supplementary Fig. 22. Absorption spectra of $50 \mu \mathrm{M} \mathrm{2}^{+}$in the dark (pure $E$ - isomer, black line) and at the photostationary state $\left(\lambda_{\text {irr }}=287 \mathrm{~nm}\right.$, red line), and absorption spectra of a $50 \mu \mathrm{M}$ mixture of $\mathbf{1}$ and $\mathbf{2}^{+}$in the dark (pure $E$ - isomer, blue line) and at the photostationary state $\left(\lambda_{\text {irr }}=286 \mathrm{~nm}\right.$, green line $)\left(\mathrm{CH}_{2} \mathrm{Cl}_{2}\right.$, r.t.). 


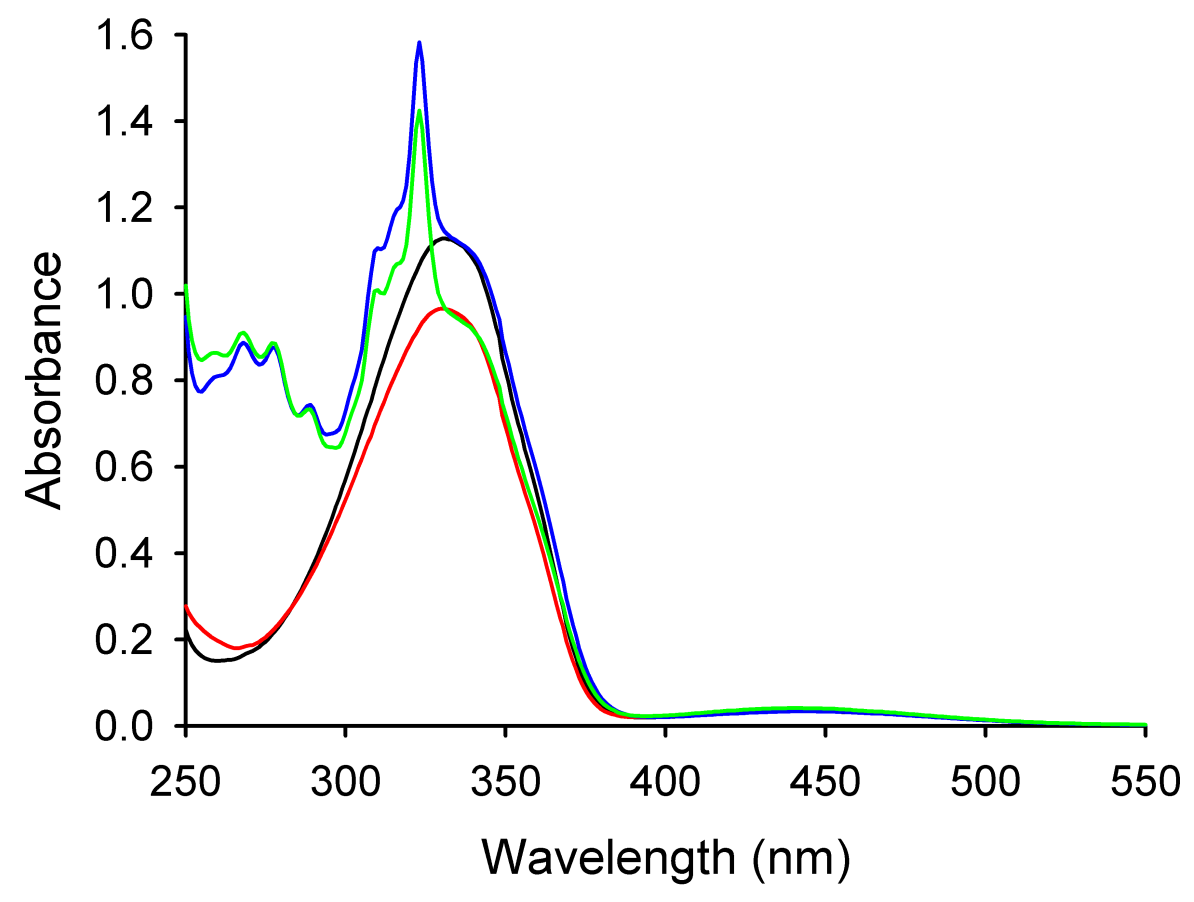

Supplementary Fig. 23. Absorption spectra of $50 \mu \mathrm{M} \mathrm{2}^{+}$in the dark (pure $E$ - isomer, black line) and at the photostationary state $\left(\lambda_{\text {irr }}=436 \mathrm{~nm}\right.$, red line), and absorption spectra of a $50 \mu \mathrm{M}$ mixture of $\mathbf{1}$ and $\mathbf{2}^{+}$in the dark (pure $E$ - isomer, blue line) and at the photostationary state $\left(\lambda_{\text {irr }}=436 \mathrm{~nm}\right.$, green line) $\left(\mathrm{CH}_{2} \mathrm{Cl}_{2}\right.$, r.t.).

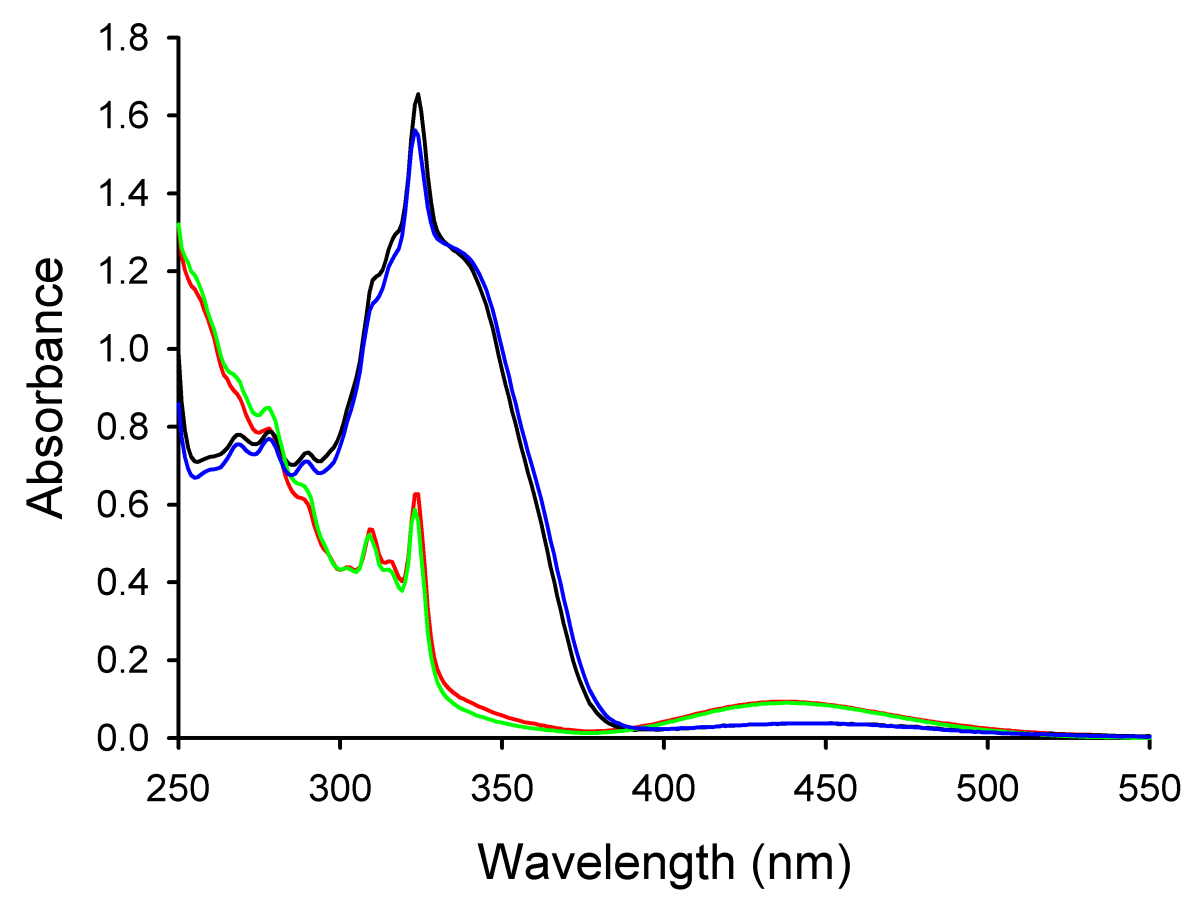

Supplementary Fig. 24. Absorption spectra of the sum of $55 \mu \mathrm{M} \mathbf{1}$ and $\mathbf{2}^{+}$in the dark (pure $E$ - isomer, black line) and at the photostationary state $\left(\lambda_{\text {irr }}=365 \mathrm{~nm}\right.$, red line) and absorption spectra of a $55 \mu \mathrm{M}$ mixture of the two components in the dark (pure $E$ - isomer, blue line) and at the photostationary state $\left(\lambda_{\text {irr }}=365 \mathrm{~nm}\right.$, green line) $\left(\mathrm{CH}_{2} \mathrm{Cl}_{2}\right.$, r.t.). 


\section{References}

1. Pedersen, C. J. J. Am. Chem. Soc. 89, 7017 (1969).

2. Baroncini, M., Silvi, S., Venturi, M. \& Credi, A. Angew. Chem. Int. Ed. 51, 4223 (2012).

3. Montalti, M., Credi, A., Prodi, L. \& Gandolfi, M. T. Handbook of Photochemistry - Third Edition (CRC Press, 2006).

4. Binstead, R.A. SPECFIT (Spectrum Software Associates, Chapel Hill, USA, 1996).

5. Credi, A. \& Prodi, L. J. Mol. Struct., in press; DOI: 10.1016/j.molstruc.2014.03.028.

6. Klán, P. \& Wirz, J. Photochemistry of Organic Compounds: From Concepts to Practice (Wiley, New York, 2009) p. 117.

7. Astumian, R. D. Phys. Chem. Chem. Phys. 9, 5067 (2007).

8. Coskun, A., Banaszak, M., Astumian, R. D., Stoddart, J. F. \& Grzybowski, B. A. Chem. Soc. Rev. 41, 19 (2012). 